\title{
Factors affecting the outputs and costs of community-based distribution of family planning services in Tanzania
}

\author{
Jane Chege \\ Population Council \\ Naomi Rutenberg \\ Population Council \\ Barbara Janowitz \\ Andrew Thompson
}

Follow this and additional works at: https://knowledgecommons.popcouncil.org/departments_sbsr-rh

Part of the Demography, Population, and Ecology Commons, Health Services Research Commons, and the International Public Health Commons

How does access to this work benefit you? Let us know!

\section{Recommended Citation}

Chege, Jane, Naomi Rutenberg, Barbara Janowitz, and Andrew Thompson. 1998. "Factors affecting the outputs and costs of community-based distribution of family planning services in Tanzania." Nairobi: Population Council. 
July 1998

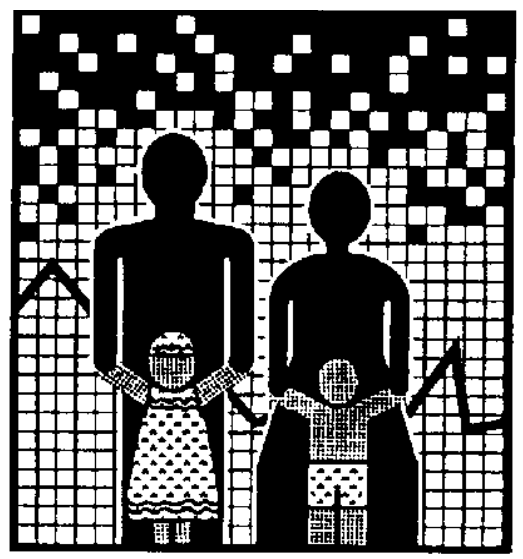

OPERATTONS

RESEARCH TECHNICAL ASSISTANCE

AFRICA PROJECT II

THE POPULATION COUNCIL

\section{Factors Affecting the Outputs and Costs of Community-Based Distribution of Family Planning Services in Tanzania}

Population Council

Jane Chege

Naomi Rutenberg

Family Health International

Barbara Janowitz

Andy Thompson 


\section{Acknowledgements}

The successful implementation of this study was possible due to the Population Council's collaboration with other organizations. These were Tanzania Center for Reproductive Health (FPU), Ministry of Health Zanzibar, UMATI, the Seventh Day Adventist (SDA) Family Planning Program, Pathfinder International Tanzania, and Family Health International (FHI). We would like to acknowledge the immense support received from Dr. Simbakalia and Mrs. Regina Lowassa of FPU. They not only ensured their Program support in the implementation of this study but also organized the dissemination workshop for the study. We would also like to thank Drs. Mapunda and Hanuni of the Ministry of Health Zanzibar, Mr. Joseph Tayali and Mr. Tenga of the SDA, Mr. Walter Mbunda and Mrs. Mtatifikoli of UMATI, and Mr. Charles Thube the Country Representative of Pathfinder International in Tanzania.

We express our sincere gratitude to all the CBD agents, field staff and accounts personnel, who spent tireless hours with us in the field providing valuable information. Thanks to Boniface Magessa, Nelson Chiziza, Adeline Kayombo, Pauline Tukay, and Veronica Shao of UMATI; Lewis Makengo and Saada Rajab Khatib of the SDA; Maryam Ali of the MOH Zanzibar; Stella Msemakwel, Christine Mayegar, Bernadata Kilala, Mwita and Mandiga of the FPU.

In addition, thanks to the members of the field research team Mrs. Biubwa Suleiman, Mr. Rashid Khamis and Mr. Clement Kihinga for dedicated participation in the fieldwork, and to Simon Kamau for patiently and joyously driving the team through rough terrain and roads for long hours. We express our thanks to Mercy Mugo of the University of Nairobi for helping with data entry and analysis of the cost component of this study.

Last but not least, we would like to thank our colleagues in USAID and the Africa OR/TA II Project for their intellectual support in reviewing the study's draft proposal and report. 


\section{ACRONYMS}

$\begin{array}{lll}\text { CBD } & - & \text { Community-based Distribution } \\ \text { CEA } & - & \text { Cost Effectiveness Analysis } \\ \text { CPR } & - & \text { Contraceptive Prevalence Rate } \\ \text { FGDs } & - & \text { Focus Group Discussions } \\ \text { FHI } & - & \text { Family Health International } \\ \text { FP } & - & \text { Family Planning } \\ \text { FPU } & - & \text { Family Planning Unit } \\ \text { IEC } & - & \text { Information, Education and Counseling } \\ \text { IGAs } & - & \text { Income Generating Activities } \\ \text { IP } & - & \text { Integrated Project } \\ \text { MCH } & - & \text { Maternal-Child Health } \\ \text { MCHA } & - & \text { Maternal-Child Health Assistant } \\ \text { MOH } & - & \text { Ministry of Health } \\ \text { NGOs } & - & \text { Non-governmental Organizations } \\ \text { PHC } & - & \text { Primary Health Care } \\ \text { PHS } & - & \text { Population and Health Services } \\ \text { TFTU } & - & \text { Tanzania Federation of Trade Unions } \\ \text { Tshs } & - & \text { Tanzania Shillings } \\ \text { USAID } & - & \text { United States Agency for International Development }\end{array}$




\section{The Population Council}

The Population Council seeks to help improve the well-being and reproductive health of current and future generations around the world and to help achieve a humane, equitable, and sustainable balance between people and resources. The Council analyzes population issues and trends; conducts biomedical research to develop new contraceptives; works with public and private agencies to improve the quality and outreach of family planning and reproductive health services; helps governments to influence demographic behavior; communicates the results of research in the population field to appropriate audiences; and helps build research capacities in developing countries. The Council, a nonprofit, nongovernmental research organization established in 1952, has a multinational Board of Trustees; its New York headquarters supports a global network of regional and country offices.

\section{Africa OR/TA Project II}

The overall objective of the Africa OR/TA Project II is to broaden understanding of how to improve family planning services in Sub-Saharan Africa, and to apply operations research and technical assistance to improve services by:

- increasing access to a full range of family planning services and methods;

- developing service delivery strategies that are client-oriented and acceptable to various population groups;

- improving the operations of programs to make them more efficient and financially sustainable;

- improving the quality of services;

- strengthening the capabilities of family planning program managers to use operations research to diagnose and solve service delivery problems.

This project was supported by the Population Council's Operations Research and Technical Assistance Project II, Project No. 936-3030 funded by the United States Agency for International Development (USAID). 


\section{TABLE OF CONTENTS}

EXECUTIVE SUMMARY........................................................................................

I BACKGROUND AND PROBLEM IDENTIFICATION ..................................... 1

I.1 CBD Programs in Tanzania ………….......................................................... 1

I.2 Problem Identification and Rationale For the Study ………................................ 6

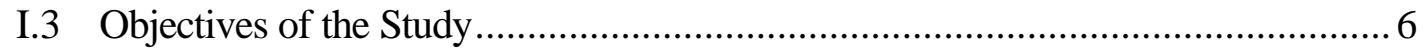

I.4 Study Design and Methodology ...................................................................... 6

II MEASURING AND COMPARING PROGRAM OUTPUTS ..........................10

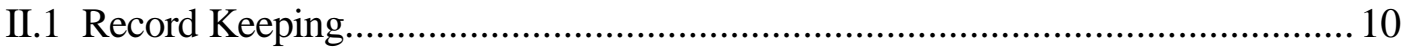

II.2 Indicators of Program Output ..................................................................... 11



III FACTORS ACCOUNTING FOR VARIANCE IN

PROGRAM PERFORMANCE........................................................................20

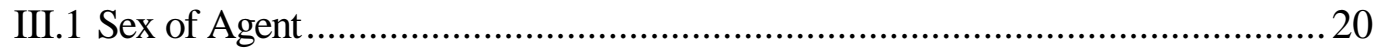

IV THE COST EFFECTIVENESS OF REIMBURSEMENT SCHEMES ...........34

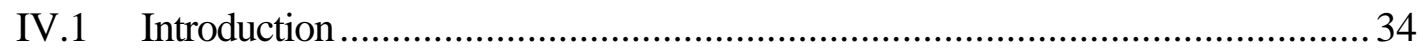

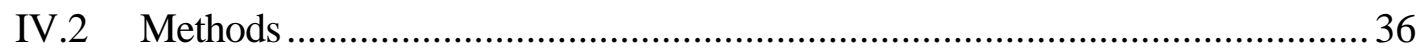

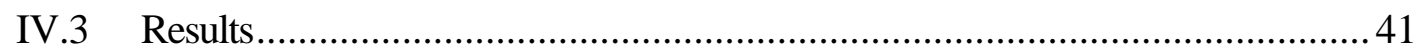

$\mathrm{V}$ CONCLUSIONS AND RECOMMENDATIONS FOR STRENGTHENING CBD PROGRAMS..................................................................47

V.1 Findings on Program Limitations ....................................................................4

V.2 Major Findings on Factors Related to

Program Output and Effectiveness ..................................................................... 48

V.3 Major Findings on Program Costs and

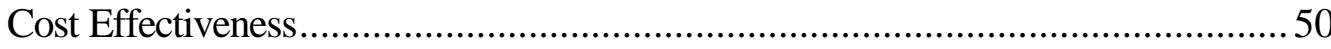

Appendix I. Evaluating the Impact of Annualizing Initial

Training Costs Over Different Time Periods ................................................51 


\section{EXECUTIVE SUMMARY}

This study set out to assess the cost-effectiveness of reimbursement schemes for communitybased distribution (CBD) programs in Tanzania. The study answers the question whether agents who receive monetary incentives perform better and are more cost-effective than those that receive non-monetary incentives. The fieldwork was undertaken in April and May 1997. The data that forms the basis of the analysis was collected from four CBD programs. These programs vary in their remuneration schemes and status of their CBD agents, size, geographical coverage, the range of activities undertaken by the agents, and supervision and management structures. One of the programs is urban-based, another is rural-based, while two are rural-based but have some urban sites.

The results of the study indicate that CBD agents who receive monetary remuneration see more clients and generate more Couple Years of Protection (CYP) than those provided with nonmonetary incentives. Further, the study found that the program relying on part-time volunteer agents who receive non-monetary remuneration in the form of income generating activities (IGAs) is the most cost-effective. However, we cannot wholly attribute the variance in program performance to the impact of remuneration. The study found that in addition to remuneration, there are a number of other programmatic factors that account for variances in program output performance and cost effectiveness. Understanding these factors is important in guiding decision making about future planning, resource allocation and technical assistance for CBD programs in Tanzania. These factors and their programmatic recommendations are given below.

\section{A. Recording and Reporting CBD Program Outputs}

\section{- The existing systems of keeping records and reporting are inadequate:}

- While more than 20 percent of CBD agents' time is spent providing information, counseling and referral services for Maternal-Child health $(\mathrm{MCH})$, Primary Health Care (PHC) and other reproductive and sexual health issues, not all programs keep records of these activities.

- Consequently, use of the number of family Planning (FP) acceptors, referrals, and CYP generated from FP services as only indicators of CBD program performance is limited.

- In both the Tanzania mainland and Zanzibar Ministry of Health programs, CBD output records are not available at all the supervision and management levels. This inhibits their use in continuous monitoring and evaluation of program performance at all levels.

- Programs vary in their definition of a new FP user. Consequently, it is inappropriate to use this indicator when comparing program performance. 


\section{Recommendations for Strengthening CBD Record Keeping and Reporting}

(a) Each Program should review its reporting format and procedures to ensure that all the reproductive and general health services provided by the CBD agents are recorded.

(b) Records must be made available and utilized in decision making at all management and supervisory levels.

(c) All programs require technical assistance in establishing computerized record keeping for ease in information storage, retrieval and use.

(d) In addition, the FPU needs to develop guidelines on a national reporting system and keep records on outputs of the CBD programs operating in the country. This will be valuable information to help in decision making about the expansion of the CBD Program in the country.

\section{B. Program Outputs}

- The expansion of the CBD training curriculum to include reproductive and sexual health as well as MCH issues is a move in the right direction:

- Agents are happy to provide a wide range of services.

- Agents providing integrated FP and reproductive or Primary Health Care services have higher output performance than those providing only FP services.

- Agents who have not been trained in all these services requested updates because the communities they serve request these services.

- Although agents from all programs have more impact as a source of supply for nonclinical methods than as referrals for clinical methods, programs vary in the methods on which they place more emphasis:

- In programs having both male and female agents, the female agents' performance was generally better than that of their male counterparts particularly for pill distribution. However, male agents distributed more condoms than female agents.

- All agents see more non-clinical method clients than referral agent clients. However, the SDA agents see more referral clients and generate quite high CYP from referral methods than the other programs do. 
- Program supervision and management characteristics have a higher impact on CBD output performance than demand environment factors such as agents' operation in urban or rural-based communities and high or low contraceptive prevalence rate (CPR) sites:

- In programs having both rural and urban sites, agents operating in urban sites did not necessarily perform better than their counterparts serving in rural districts.

- Within programs having both high and medium CPR sites, agents in high CPR districts did not necessarily have better performance than their counterparts operating in lower CPR areas.

- Agents identified monthly individual supervisory contacts, participation in program managed and sponsored income generating activities (IGAs), and strong community support as important motivating factors to their work.

- Programs having frequent individual supervisory contacts, IGAs and strong community participation and support of CBD activities performed better than programs lucking or weak in these factors.

- Monetary remuneration, while an important factor in motivating agents to produce higher outputs does not necessarily guarantee job satisfaction:

- Agents provided with monetary remuneration complained about inadequate remuneration more than the volunteer agents provided with non-monetary remuneration.

- Agents having IGAs, which are sponsored and managed by their program, appear to have a higher level of job satisfaction and CBD retention rates than programs without IGAs. 


\section{Recommendations for Improving Program Output Performance}

(a) $\mathrm{CBD}$ agents trained before the implementation of the expanded CBD curriculum should have refresher courses covering elements they had not covered in their initial training and agents should be offered frequent refresher courses to be up-dated on developments in reproductive and sexual health field.

(b) Programs designed to have weak or no community participation in the activities of the CBD programs should design strategies to involve community leaders in the management and running of CBD activities in their respective areas.

(c) For sustainability and increased motivation of CBD agents, programs relying on volunteer agents need to consider introducing program sponsored and managed IGAs.

(d) Programs having very few or no male CBD agents should review their recruitment policy and practices with a view to increasing male participation as service providers and users of community-based reproductive health services.

(e) Programs should implement the national CBD supervisory guidelines and reduce the ratio of number of CBD agents to one supervisor in areas where supervisors have a heavy workload. 


\section{Costs and Cost-effectiveness of the Programs}

- Variation in the programs' cost-effectiveness ratios cannot be attributed solely to variations in remuneration strategies. A number of other factors that could not be fully controlled affect the programs' output.

- For example, UMATI, the program relying on volunteer agents provided with nonmonetary incentives, is the most cost-effective program

- There are significant variations in program's cost structure, which affect costeffectiveness.

- For example, SDA spends a large proportion of its budget on remuneration, FPU on supervision and training, and UMATI in training. FPU training costs are significantly higher than those of UMATI and SDA.

\section{Recommendations for Improving Cost-effectiveness}

(a) Programs that pay little or no compensation, but have high training, supervision, and other costs to support their agents, may want to consider using more of their budget to compensate agents while reducing other costs.

(b) Improving factors such as supervision and community participation in and support of CBD activities will raise output and consequently improve cost-effectiveness.

(c) In preparing for declines in donor funding, programs need to take a broader focus than simply slashing salaries or payments to agents. The full budget should be examined so as to determine how the program could best survive with lower funding from donors.

(d) To learn how remuneration affects cost-effectiveness, operations research designs that control for program differences not associated with remuneration are required. 


\section{BACKGROUND AND PROBLEM IDENTIFICATION}

\section{I.1 CBD Programs in Tanzania}

Community-based distribution of contraceptives (CBD) is a non-clinical family planning service delivery strategy. This strategy relies mainly on the use of trained paid or unpaid community members to provide family planning (FP) services and information at convenient locations in homes, workplace, villages, markets or other public places. The CBD strategy has a high potential for increasing FP knowledge, acceptability and accessibility of modern contraceptive methods in countries with low demand and insufficient clinical services. The strategy is based on the premises that:

- Making contraceptives available at convenient locations reduces both the time and financial costs a client would incur while seeking services at clinical settings.

- Using community members as FP service providers increase the accessibility of services by reducing the social distance between the client and the provider.

Tanzania has relatively limited experience with CBD in terms of the age of the programs and geographical coverage. Most programs were developed between 1992 and 1993, although UMATI $^{1}$ was the first to implement a CBD program, in 1988. Currently, seven organizations (governmental, NGO and church-based) are running CBD programs in Tanzania: UMATI; the Seventh Day Adventist Church (SDA); Shirika La Uchumi La Wanawake Tanzania (SUWATA); Population and Health Services (PHS); the Tanzania Federation of Free Trade Unions (TFTU); the Tanzania Ministry of Health, Family Planning Unit (FPU) project; and the Ministry of Health, Zanzibar. $^{2}$ By December 1996, the programs were active in 22 of the 104 districts that comprise Tanzania mainland and Zanzibar Island. Out of the country's 25 regions, the CBD programs were providing services in 17 regions.

Apart from the National CBD Strategy developed in 1993, the CBD programs in Tanzania operate without clear cut policy guidelines on program implementation. ${ }^{3}$ Consequently, each CBD program has developed its own implementation strategies, although the mainland Ministry of Health Family Planning Unit (FPU), in its capacity as strategy coordinator, is developing guidelines. So far, the FPU has developed a national CBD protocol, a supervision manual and a training curriculum to guide both government and NGO CBD programs. The National CBD training curriculum, implemented since 1997, ensures that CBD programs integrate FP services with appropriate

\footnotetext{
1 The IPPF affiliate.

2 While politically part of the United Republic of Tanzania, Zanzibar maintains several separate government structures and policies. Thus, the United Republic of Tanzania has two independent Ministries of Health, one for mainland Tanzania and another for the Zanzibar islands.

3 Although not designed specifically for CBD programs, the Tanzania National Policy Guidelines and Standards for Family Planning Service Delivery and Training provide some guidelines on the provision of CBD and commercial social marketing of FP services.
} 
reproductive health and child survival services. However, there is still flexibility on issues such as recruitment, status and remuneration of CBD agents and strategies.

Variability in organizational structure is one of the striking characteristics of CBD programs in Tanzania (see table I.1). The CBD programs vary according to:

Geographical Coverage and Number of Agents: Some programs such as UMATI, FPU, MOH Zanzibar and SDA have relatively many CBD agents and cover large populations in many districts. Others, such as TFTU, PHS and SUWATA, have comparatively few CBD agents and target specific populations mainly in urban areas.

Agent Recruitment: The process of, and the criteria for, selecting CBD agents also vary. Some programs, such as UMATI, FPU, SUWATA and SDA, have a comparatively high level of community participation in the selection of CBD agents, whereas others, such as MOH Zanzibar, rely on program staff to identify suitable candidates. The criteria for selecting CBD agents do not differ significantly among the programs except for sex and educational level. The FPU, UMATI and PHS programs lay emphasis on recruiting both male and female agents (preferably in equal numbers), while the SDA, SUWATA and MOH Zanzibar programs rely mainly on female agents. With an exception of the MOH Zanzibar that recruits some illiterate agents, all the programs require a minimum of 7 years of schooling.

Supervision: The SDA and UMATI programs have full-time supervisors, whereas supervisors in the FPU, MOH Zanzibar, PHC, SUWATA and TFTU programs also have clinic responsibilities. While other programs use trained health personnel as immediate CBD supervisors, UMATI and SUWATA rely on 'promoted CBD agents' who supervise as volunteers. The FPU, MOH Zanzibar, SDA, TFTU and PHS agents have links with their organizations' clinics for supervision, referral and supply of contraceptives. For the UMATI and SUWATA programs, some agents are linked to their clinics while others are 'free standing'; the 'free standing' agents receive their supervision from the nearest agency office and are linked for referral to clinics of other agencies.

Training: CBD agents from all the programs receive formal 'classroom' training before embarking on their CBD activities. The SDA program also conducts on-the-job training for agents recruited to replace a dropout agent. Before introduction of the standard curriculum in 1997, the programs used varying protocols and training curricula, and the duration and content of the training varied by program. MOH Zanzibar had only three days of training covering some elements of FP counseling and contraceptive supply, the FPU, SUWATA, TFTU, UMATI and SDA programs had three weeks of training, while the PHC program had six weeks. With the exception of the MOH Zanzibar program, all programs have bi-annual refresher courses. The FPU, SUWATA and TFTU training courses are more focused on family planning, while UMATI, SDA and PHC agents also receive training in some other elements of reproductive health and maternal and child health $(\mathrm{MCH})$. In addition, UMATI agents receive training on some environmental sanitation issues and on management of income generating activities (IGAs). 
Range of CBD Activities: All CBD agents in Tanzania provide non-clinical methods (pills, condoms and spermicides), information, education and communication (IEC) in FP, and referral service to clinics for clinical methods. Some programs have combined these services with a range of reproductive health and maternal and child health $(\mathrm{MCH}) /$ primary health care (PHC) services UMATI, SDA, PHC and SUWATA CBD programs have provided some integrated reproductive health and PHC services even before the new curriculum.

Approaches to reach the target community: All programs use the home-visit approach to reach their clients. However, TFTU ${ }^{4}$ and PHC have workplace peer educators who provide services at their workplace. The FPU, UMATI, PHC, SUWATA and SDA programs supplement home visits with occasional group meetings. FPU, UMATI and SUWATA agents use drama, song and dance in addition to printed materials to promote IEC messages in public meetings.

Remuneration of CBD Agents: Except for the MOH Zanzibar program ${ }^{5}$, all the CBD programs provide some non-monetary incentives (in form of working tools) to their CBD agents. The tools provided are:

- $\quad$ Bicycles (FPU, UMATI, SDA)

- Contraceptive storage boxes and bags, umbrellas, gum boots and writing materials (FPU, SDA, UMATI, SUWATA)

- Praise for best agent and study tours and CBD badges (FPU)

- Uniforms (UMATI, SDA).

In addition to these non-monetary incentives, all CBD programs (except the $\mathrm{MOH}$ Zanzibar program) provide some monetary incentives to their agents. There are four different forms of financial remuneration schemes in use in Tanzania:

1) Salaried Workers: The SDA program relies on full-time salaried employees, who receive a salary of Tsh. 17,500 (\$28) per month.

2) Monthly allowance: SUWATA, TFTU and FPU rely on part-time volunteer agents who receive a monthly allowance. SUWATA and TFTU agents receive a monthly allowance of Tsh. 5,000. When funds are available, FPU provides its agents with a monthly bicycle allowance (to assist in bicycle maintenance) of Tsh. 1000.

3) Piece rate basis: PHC relies on part-time volunteer agents who receive their pay on piece rate basis. The agents receive Tsh. 1000 for every client they recruit for long term methods (voluntary surgical contraceptives). In addition to their monthly allowance, TFTU CBD agents and workplace peer educators market SALAMA condoms and keep the profit.

$4 \quad$ A large number of TFTU agents (42) provide services at the community level. Another group of peer educators (18) provides FP services at their places of work.

5 During the period of their initial training, agents recruited before late 1996 received a transport refund and a bag. Agents also received calendars when available. With effect from this year (1997), the program has started to provide bicycles to newly recruited, and best performing CBD agents. 
4) Support for Income Generating Activities (IGAs): UMATI relies on volunteer parttime CBD agents who do not receive direct monetary pay but receive help to enable them generate income. The FPU and UMATI programs both train and help agents to establish IGAs and in addition, UMATI provides IGA materials. A group of CBD agents can receive a tractor, milling machine, sewing machines, vehicle for transportation or masonry and carpentry kits. The CBD agents and some community members, with the assistance of the program staff manage the IGAs. They use the items to provide services to community members at a price. Profits from the IGAs are re-invested or shared among the CBD agents and participating community members. 
Table I.1: Characteristics of CBD Programs in Tanzania

\begin{tabular}{|c|c|c|c|c|c|c|c|}
\hline Agency & Sector & Location & CBD status \& pay & Supervision & $\begin{array}{c}\text { Year } \\
\text { started }\end{array}$ & $\begin{array}{c}\text { \# of agents } \\
12 / 96\end{array}$ & Coverage \\
\hline UMATI & NGO & Rural & $\begin{array}{l}\text { Part-time/ volunteer/ } \\
\text { Incentive/IGA }\end{array}$ & $\begin{array}{l}\text { Full-time/free } \\
\text { standing/clinic } \\
\text { linked }\end{array}$ & 1988 & 683 & 5 Regions, 6 districts \\
\hline FPU & Public & $\begin{array}{c}\text { Rural \& } \\
\text { Urban }\end{array}$ & $\begin{array}{c}\text { Part-time/ } \\
\text { Volunteer/incentive/ } \\
\text { allowance } \\
\end{array}$ & $\begin{array}{l}\text { Part-time/clinic } \\
\text { linked }\end{array}$ & 1993 & 663 & 5 Regions, 1 urban \& 9 rural districts \\
\hline SDA & $\begin{array}{l}\text { Church- } \\
\text { based } \\
\text { NGO }\end{array}$ & Urban & $\begin{array}{l}\text { Full-time/salary/ } \\
\text { incentives }\end{array}$ & $\begin{array}{c}\text { Full-time/clinic } \\
\text { linked }\end{array}$ & 1993 & 189 & 5 Regions, 6 urban districts \\
\hline $\begin{array}{c}\mathrm{MOH} \\
\text { Zanzibar }\end{array}$ & Public & $\begin{array}{c}\text { Rural \& } \\
\text { Urban }\end{array}$ & Part-time Volunteer & $\begin{array}{c}\text { Part-time/clinic } \\
\text { linked }\end{array}$ & 1993 & 114 & 2 Regions, 1 urban $\& 9$ rural districts \\
\hline PHS & NGO & Urban & $\begin{array}{c}\text { Part-time/ Volunteer/ } \\
\text { piece rate }\end{array}$ & $\begin{array}{c}\text { Part-time/clinic } \\
\text { linked }\end{array}$ & 1990 & 24 & $\begin{array}{c}2 \text { Regions, } 4 \text { urban \& Peri urban } \\
\text { districts }\end{array}$ \\
\hline SUWATA & NGO & Urban & $\begin{array}{l}\text { Part-time/ volunteer/ } \\
\text { Incentive/ allowance }\end{array}$ & $\begin{array}{c}\text { Part-time/free } \\
\text { standing/clinic } \\
\text { linked } \\
\end{array}$ & 1995 & 25 & 1 Region, 2 Urban Peri-urban districts \\
\hline TFTU & NGO & Urban & $\begin{array}{c}\text { Part-time/ volunteer/ } \\
\text { incentives/ } \\
\text { allowance/ } \\
\text { piece-rate }\end{array}$ & $\begin{array}{l}\text { Part-time, clinic } \\
\text { linked }\end{array}$ & 1994 & 60 & 1 Region, 1 urban district \\
\hline
\end{tabular}




\section{I.2 Problem Identification and Rationale for the Study}

This diversity in CBD approaches in Tanzania raises fundamental questions relating to the effectiveness, and cost-effectiveness, of the various models in existence. To guide its future decisions in allocation of resources for CBD programs, USAID/Tanzania requested the Africa OR/TA Project II to undertake this study to provide answers to two questions:

- Do CBD agents who receive monetary pay distribute more contraceptives and see more clients than those given only non-monetary incentives?

- Are programs that pay their agents a monthly salary more cost-effective than programs that give a monthly allowance or those that give only non-monetary incentives to their agents?

A better understanding of the performance and the factors accounting for variances in program effectiveness in Tanzania will provide useful information to program managers and donors with an interest in CBD implementation in the country. The study will provide information to program managers to guide their decisions on future directions for the structure and organization of their programs.

\section{I.3 Objectives of the Study}

The study examines the effectiveness, cost-effectiveness and factors related to the costeffectiveness of four CBD programs based on costs and outputs for 1995 and 1996. Specifically the study:

- describes the geographical coverage, strategies, operational structure and policies for each CBD model;

- measures and compares the output of CBD models;

- measures and compares the cost of CBD models;

- calculates and compares the relative cost-effectiveness of CBD models.

\section{I.4 Study Design and Methodology}

\section{I.4.1 Study Design}

The seven CBD programs currently operating in Tanzania were categorized into five broad categories based on their remuneration schemes. It was not possible to include all seven programs in the study; the four programs examined are shown in bold.

- Full-time agents, given a salary and non-monetary incentives and supervised/attached to their organization's clinic - SDA program (church-based)

- Part-time volunteers given a monetary allowance and non-monetary incentives and supervised/attached to their organization's clinic - FPU CBD program (public sector) and 
SUWATA (NGO sector). SUWATA was omitted because the program had been operating for less than three years.

- Part-time volunteers without a monthly allowance but provided with non-monetary incentives and income generating activities (IGAs) - UMATI (NGO sector). Some UMATI CBD sites are not directly linked to an UMATI clinic (free standing) while other sites are linked to and supervised from an UMATI clinic.

- Part-time volunteers who do not receive any allowance or incentives and are supervised/attached to their organization's clinic -MOH Zanzibar program (public).

- Part-time volunteers paid on a piece rate basis - TFTU and PHS (NGO sector). Meaningful comparisons of TFTU and PHS, which use a piece-rate remuneration strategy with the other organizations that are either paying a monthly salary/allowance or not paying are not possible due to the limited population coverage and number of agents involved.

\section{I.4.2 Sampling}

As highlighted above, CBD programs in Tanzania vary in many ways besides remuneration schemes. To control for variability in program performance (which may not relate to remuneration modalities), it is important to compare program performance in districts that are comparable, in addition to comparing their performance at the national program level. The following criteria were used to select comparable districts:

- Family Planning Demand Environment. To control for the possibility that CBD program performance may be affected by existing socio-cultural factors affecting demand for family planning, districts having comparable contraceptive prevalence rates (CPR) and family planning demand were selected for comparison. ${ }^{6}$ Using information from the latest Tanzania $\mathrm{DHS}^{7}$ on CPR of modern contraceptive methods for the regions, the regions covered by CBD agents were categorized as either having low (1\% to $10 \%)$, medium (11\% to $19 \%)$, or high (20\% and above) CPR sites. CBD sites from different programs were paired for comparison purpose. The paired districts have the same CPR, family planning demand level, and unmet need. ${ }^{8}$ Thus for the urban-based CBD agents, a comparison is made of the performance of agents from different organizations located in Ugunja and Tabora urban. For the rural sites, a comparison is made between FPU agents in Dodoma and UMATI agents in Morogoro and between FPU and UMATI agents operating in Iringa region (see table 1.2).

\footnotetext{
$6 \quad$ Although the CPR of a region may not necessarily reflect the CPR of all the districts constituting that region, the region's CPR was used to represent the selected district due to the lack of information about CPR at the district-level.

7 Tanzania Demographic and Health Survey, 1996. Bureau of Statistics Planning Commission and Macro International Inc.

$8 \quad$ However, Dodoma and Musoma have a higher FP unmet need than Morogoro and Tabora respectively.
} 
- Population density. Population density has an effect on agents' travel time. Agents operating in high densely populated areas need to cover shorter distances to visit their clients than those living in sparsely populated areas do. For comparison with programs in rural areas, the 1988 Population Census population density (number of persons per square kilometer) was used to identify rural districts whose population density does not differ significantly.

- Length of time program has been in operation in the district. Only those districts where a program has been operating for a minimum of two years were included in the study.

These criteria were used to select eight districts for four pair-wise comparisons. A ninth high CPR site was also selected from the UMATI, the only program with a site with high CPR and population density site that met all selection criteria. This site was included to test whether program performance in high CPR and population density rural sites differed significantly from the low or medium CPR and population density sites. The sampled districts and the information used to select them are shown in Table I.2.

Table I.2: $\quad$ Sample Districts

\begin{tabular}{|l|l|c|c|c|c|l|}
\hline Program & Region & CPR & $\begin{array}{c}\text { Total FP } \\
\text { demand }\end{array}$ & $\begin{array}{c}\text { Unmet } \\
\text { need }\end{array}$ & $\begin{array}{c}\text { Population } \\
\text { Density }\end{array}$ & District \\
\hline FPU (Rural) & Iringa & 7.7 & 25.7 & 14.7 & 21 & Mufindi \\
UMATI(Rural) & Iringa & 7.7 & 25.7 & 14.7 & 21 & Iringa \\
\hline FPU (Rural) & Dodoma & 11.4 & 34.3 & 21.3 & 21 & Dodoma \\
UMATI(Rural) & Morogoro & 13.3 & 34.4 & 17.2 & 17 & Morogora \\
\hline SDA (Urban) & Mara & 5.4 & 33.9 & 27.1 & N/a & Musoma \\
FPU (Urban) & Tabora & 11.1 & 33.3 & 16.7 & & Tabora \\
\hline SDA (Urban) & Ugunja & 9.2 & 39.4 & 29.5 & N/a & Urban \\
MOH Zanzibar (urban) & Ugunja & 9.2 & 39.4 & 29.5 & & Urban \\
\hline UMATI & Kilimanjaro & 23.7 & 51.4 & 13.7 & 83 & Hai \\
\hline
\end{tabular}




\subsubsection{Data Collection and Analysis}

The study used several data collection methods including:

- In-depth interviews with program managers, staff and CBD supervisors.

- Focus group discussions (FGDs) with groups of CBD agents in each sample district.

- A review of program documents.

- A review of program service statistics and financial records.

- Time sheets on daily activities and time spent on each - filled by immediate CBD supervisors and sample CBD agents.

Program managers, accountants and CBD supervisors provided documents and service statistics on program outputs and costs. Review of program documents, in-depth interviews with program staff and FGDs with CBD agents were used to collect data on coverage, supervision structures and policies of each CBD program. In each sample district, FGDs were conducted with two separate groups comprising between five and ten CBD agents each.

The cost data were processed and analyzed using EXCEL program. EPI-INFO was used to enter data from the CBD agents' and supervisors' timesheets and all quantitative data, and SPSS was used to analyze this data. The quantitative data analysis has used descriptive bivariate and survival statistics. The presentation of the findings in subsequent chapters follows the major objectives of the study. 


\section{MEASURING AND COMPARING PROGRAM OUTPUTS}

\section{II.1 Record Keeping}

To compare CBD outputs of different programs, it is desirable to use output measures that have the same definition across the programs. Thus, variations and gaps in recording and reporting of CBD outputs restrict the comparative analysis possible for this study. Some of the limitations in the program records ${ }^{9}$ for comparative analysis are noted below:

Variations in CBD output records kept. Due to variations in the activities undertaken there are variations in the CBD output records kept by various programs. For example, SDA and UMATI keep records of IEC contacts through home visits, group and public meetings. However, although FPU agents undertake similar activities, they do not keep records of IEC contacts. New and revisit CBD supply method contacts were not dis-aggregated by method for the MOH Zanzibar program, making it impossible to measure client contacts by method for this program.

Variations within the level at which records are available. As table II.1 shows, not all records kept by CBD agents are available at the program headquarters. Consequently, it was not possible to obtain records on FPU program outputs for 1996 except for the data collected in the sample districts. The $\mathrm{MOH}$ publication of reports presented during the $3^{\text {rd }} \mathrm{CBD}$ annual review meeting was the source of the 1995 individual district records for FPU. MOH Zanzibar CBD output records are aggregated with clinic records at the clinic, district and headquarters level. An examination of the clinic records kept in each static health facility that has CBD agents attached yielded information on CBD outputs. Due to the large number of static health facilities with attached CBD agents in Zanzibar, it was only feasible to identify CBD outputs for Ugunja.

Variations within the same program in records reported. Some FPU districts report on new and revisit client contacts by method and volume of contraceptives distributed. Others report only clients by method for one specific year. Still other districts report the total number of clients from the date the CBD activities were initiated in the district. For those districts not reporting volume of contraceptives, there were difficulties in calculating Couple Years of Protection (CYP) and an aggregate of all CBD clients could not be used to represent a single year.

Due to difficulties in ascertaining the correctness of output records provided by the programs, this study operated on the assumption that, through their supervisory activities, program supervisors check the accuracy of the output reports received from the agents. To verify the accuracy of the records received from the program managers would require going through the client registers of all the agents and following up on their clients to ensure that the clients exist and are provided with the services. In view of the large number of CBD agents, this was not possible. Using each program's guidelines on the number of contraceptives to be distributed at each contact, it was clear for all the programs that the clients served would have generated a higher volume of contraceptives than the reported volume of contraceptives. However, this cannot be attributed solely to falsification of outputs because the realities of working in the field do not always allow the agents to strictly follow their respective program's distribution policy. 
Variations in definition of 'new client'. For some programs, new clients may include both new users, and continuing FP users who are new to the program, while for others this includes only new FP users. FPU and SDA define a new client as any client served by the CBD for the first time. ${ }^{10}$ $\mathrm{MOH}$ Zanzibar and UMATI define a new client as any person who has never used modern contraceptive methods before.

\section{Table II.1 Program Indicators Recorded at Different Program Levels}

\begin{tabular}{|l||c|c|c||c|c|c||c|c|c||c|c|c|}
\hline \multicolumn{1}{|c|}{ Indicator } & \multicolumn{3}{c||}{ FPU } & \multicolumn{3}{c||}{ UMATI } & \multicolumn{3}{c||}{ SDA } & \multicolumn{3}{c|}{ MOH Zanzibar } \\
\hline $\begin{array}{l}\text { CBD Catchment } \\
\text { Area Population }\end{array}$ & $\checkmark$ & $\checkmark$ & $\checkmark$ & $\checkmark$ & & & $\checkmark$ & & & & & \\
\hline $\begin{array}{l}\text { Women of } \\
\text { Reproductive Age }\end{array}$ & $\checkmark$ & $\checkmark$ & $\checkmark$ & $\checkmark$ & & & $\checkmark$ & & & & & \\
\hline $\begin{array}{l}\text { CPR before \& after } \\
\text { CBD inception }\end{array}$ & $\checkmark$ & $\checkmark$ & $\checkmark$ & & & & & & & & & \\
\hline Women at risk & & & & $\checkmark$ & $\checkmark$ & & & & & & & \\
\hline Total CBD clients & $\checkmark$ & $\checkmark$ & $\checkmark$ & $\checkmark$ & & & $\checkmark$ & & & $\checkmark$ & & \\
\hline $\begin{array}{l}\text { FP New \& Revisit } \\
\text { client contacts }\end{array}$ & $\checkmark$ & $\checkmark$ & & $\checkmark$ & $\checkmark$ & $\checkmark$ & $\checkmark$ & $\checkmark$ & $\checkmark$ & $\checkmark$ & & \\
\hline $\begin{array}{l}\text { FP Referral clients } \\
\text { W }\end{array}$ & $\checkmark$ & $\checkmark$ & & $\checkmark$ & $\checkmark$ & $\checkmark$ & $\checkmark$ & $\checkmark$ & $\checkmark$ & $\checkmark$ & & \\
\hline $\begin{array}{l}\text { Non FP Referral } \\
\text { clients }\end{array}$ & $\checkmark$ & $\checkmark$ & & $\checkmark$ & $\checkmark$ & $\checkmark$ & $\checkmark$ & $\checkmark$ & $\checkmark$ & & & \\
\hline $\begin{array}{l}\text { Number of clients } \\
\text { discontinuing FP }\end{array}$ & $\checkmark$ & $\checkmark$ & & $\checkmark$ & $\checkmark$ & & & & & & & \\
\hline $\begin{array}{l}\text { Contraceptives } \\
\text { distributed }\end{array}$ & $\checkmark$ & $\checkmark$ & & $\checkmark$ & $\checkmark$ & $\checkmark$ & $\checkmark$ & $\checkmark$ & $\checkmark$ & $\checkmark$ & & \\
\hline $\begin{array}{l}\text { Volume of home } \\
\text { visits }\end{array}$ & & & & $\checkmark$ & $\checkmark$ & & $\checkmark$ & $\checkmark$ & $\checkmark$ & & & \\
\hline $\begin{array}{l}\text { Number of group \& } \\
\text { public IEC meetings }\end{array}$ & & & & $\checkmark$ & $\checkmark$ & & $\checkmark$ & $\checkmark$ & $\checkmark$ & & & \\
\hline
\end{tabular}

\section{II.2 Indicators of Program Output}

Interviews with staff and examination of 1995 and 1996 service records at headquarters and at the sample districts provided the data on program outputs used in this analysis. Except for the FPU program whose total program data for 1996 was not available, the output records presented are an average of the respective program's 1995 and 1996 outputs.

10 FPU has already standardized the definition of new clients and the various programs are required to use the standardized definition. 
The comparative analysis in this study uses only those output records that are common in all the organizations to measure and compare program performance. The following three outputs are the only ones common to all CBD programs:

- New and revisit client contacts

- Referral client contacts by method

- Volume of contraceptives distributed.

However, the use of these output measures has several shortcomings.

Firstly, use of only those records that are common in all the programs is a disadvantage to programs whose agents spend time on activities other than individual client contacts and contraceptive distribution. This is particularly the case for programs whose agents undertake public or/and group IEC contacts. In addition, visits in which clients do not receive a method or referral service are not included because only SDA keeps such records.

Secondly, differences in the volume of clients met or visited do not necessarily correlate with differences in the number of clients served or differences in impact in achieving the goal of reducing unwanted pregnancies. This is mainly because there are variations in programs' policies and practice on the number of pill cycles, foaming tablets, or condom pieces provided to new and revisits client per visit. Thus, even for the same method, the number of visits required to generate one couple year of protection (CYP) from unwanted pregnancy varies depending on the program's distribution policy.

For example, the FPU and UMATI programs have a policy of providing three pill cycles to a new client and six cycles to a revisit client. SDA's policy is to provide six and twelve pill cycles, respectively. $\mathrm{MOH}$ Zanzibar agents do not provide pill cycles to new clients but refer them to the clinic for medical check-up. After receiving three re-supplies (of three cycles each) from the CBD agent, clients are required to get a medical examination and their next re-supply at the clinic. Within the same program, the quantity of pills, condoms, or foaming tablets distributed at each visit generates different amounts of contraceptive protection. ${ }^{11}$

Thirdly, assigning CYP credit for referral methods to CBD agents, which recognizes CBD agents for time spent on recruiting and counseling referral clients, leads to double counting. The clinic supplying the method also has a rightful claim to the CYP generated by CBD referral clients.

Although these output measures may not be the most comprehensive or refined indicators of program performance, for lack of better measures, the remainder of this section compares program performance on these outputs. The study compares the performance of the programs at the program and district levels both in absolute terms and in terms of output per CBD.

$11 \quad$ For example, on average in 1995 and 1996, SDA agents generated 0.34 CYP per pill visit, 0.47 CYP per condom visit, and 0.37 CYP per foaming tablets visit. UMATI generated 0.20 CYP per pill visit, 0.10 CYP in a condom visit, and 0.09 CYP per visit when foaming tablets were distributed. 


\section{II.3 Program Level Outputs}

\section{II.3.1 Client contacts}

Figure 1 shows the average annual number of client visits for the UMATI, SDA and FPU ${ }^{12}$ programs based on 1995 and 1996 data.

FIGURE 1

AVERAGE ANNUAL NUMBER OF CLIENT VISITS PER PROGRAM

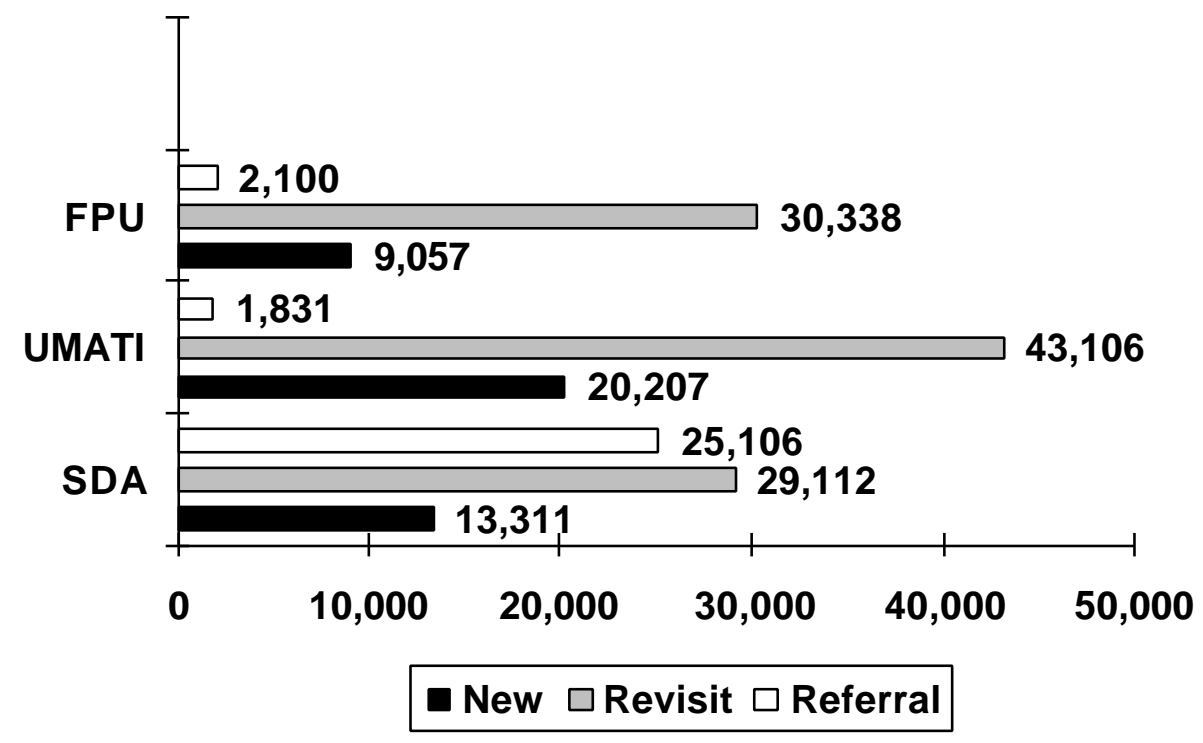

One would expect that a program having a higher number of CBD agents would have a greater volume of outputs than one with a lower number of agents. However, Figure 1 shows this is not the case. Overall, the SDA program, which had the third highest average number of active CBD agents, had the highest volume of client visits. UMATI, which had the highest average number of active CBD agents, had the highest volume of client contacts for methods supplied by CBD agents.

Table II. 2 compares programs on their method mix for referral client visits. Analysis of the data in the table shows that:

- CBD agents most frequently refer their clients for injectable contraceptives; 90 percent of all CBD referrals in the FPU program are for injectables.

- Approximately one-fifth of client referral visits from SDA and UMATI agents are for non-family planning services.

12 The MOH Zanzibar program client visit records are not dis-aggregated into new and revisit clients' contacts. The program had a total of 302 client contacts for methods supplied by CBD agents and 114 for referral methods. 
- While the NGO programs have relatively many referrals for surgical contraceptive methods and Norplant ${ }^{\circledR}$ implants, the governmental programs only occasionally refer for these methods. ${ }^{13}$ In the two years included in the analysis, FPU agents did not refer any clients for Norplant ${ }^{\circledR}$ implants and only a few clients for permanent methods of contraception. In comparison, nearly one-fifth of UMATI referrals are for Norplant ${ }^{\circledR}$ implants or voluntary surgical contraception.

Table II.2 Average Annual Program Client Visits for Referrals (1995 \& 1996)

\begin{tabular}{|c|c|c|c|c|c|c|}
\hline Referral method visit & \multicolumn{2}{|c|}{ SDA } & \multicolumn{2}{|c|}{ UMATI } & \multicolumn{2}{|l|}{ FPU } \\
\hline & Referrals & $\%$ & Referrals & $\%$ & Referrals & $\%$ \\
\hline Pill & 4,169 & 17 & 143 & 8 & 23 & 1 \\
\hline Injectables & 10,627 & 42 & 861 & 47 & 1895 & 90 \\
\hline IUCD & 1,714 & 7 & 144 & 8 & 43 & 2 \\
\hline NORPLANT® & 2,451 & 10 & 117 & 6 & 0 & 0 \\
\hline VSC & 931 & 4 & 224 & 12 & 35 & 2 \\
\hline Non-FP services $^{14}$ & 5,215 & 21 & 342 & 19 & 104 & 5 \\
\hline Total & 25,106 & 100 & 1831 & 100 & 2100 & 100 \\
\hline
\end{tabular}

\section{II.4 Average Outputs per CBD Agent}

\section{II.4.1 Average Client Contacts}

Volume of overall program outputs is not a good measure of program effectiveness because it is determined in part by the number of CBD agents in a program. Annual average output per CBD agent measures the contribution of individual CBD agents and is therefore a better indicator for comparing program effectiveness. This is obtained by dividing a program's annual outputs by the number of active $\mathrm{CBD}$ agents in the respective year. Using this effectiveness measure, the following results emerge:

- The SDA program is the most effective program. As seen in Table II.3, this program has the highest number of clients for methods distributed by CBD agents, referrals, and CYP per CBD agent. This is partly because these full-time paid SDA agents work for longer hours in a day than the part-time volunteer agents from the other programs. However, both UMATI and FPU are part-time volunteer programs with a similar number of active agents yet UMATI agents made significantly more client contacts per CBD in 1995 and 1996 than FPU agents.

- Among the rural-based CBD programs relying on volunteer part-time agents, the UMATI program has the highest outputs per CBD agent.

13 Data for MOH Zanzibar are shown in Table II.6.

14 For example, for MCH and STD/HIV services and treatment of illnesses. 
- All the programs had more re-visits than new client visits per CBD agent. UMATI and SDA have a higher percentage of new client visits (32\% and 32\%, respectively) compared to FPU $(22 \%)$.

- All programs have a considerably larger volume of visits for methods supplied by CBD agents than for referrals. However, referral client contacts per CBD account for about $37 \%$ of the total client contacts per CBD for SDA but only $3 \%$ for the UMATI and $6 \%$ for the FPU programs.

Table 11.3 Average Annual Client Contacts, Referrals and CYP per CBD Agent by Program and Method (1995 \& 1996)

\begin{tabular}{|l|c|c|c|c|c|c|}
\hline Program & \multicolumn{4}{|c|}{ Client Contacts } & \multicolumn{2}{c|}{ CYP } \\
\hline & Total & New & Revisit & Referral & Methods & Referral \\
\hline SDA & 425 & 86 & 181 & 158 & 94 & 207 \\
\hline UMATI & 132 & 41 & 87 & 4 & 19 & 10 \\
\hline FPU* & 105 & 22 & 77 & 6 & 13 & 3 \\
\hline MOH Zanzibar & 10 & N/A & N/A & 4 & 4 & 2 \\
\hline
\end{tabular}

* 1995 only

Figure 2 and Table II.4 presents the average annual number of client visits per CBD according to the method supplied at the visit. FPU and MOH Zanzibar programs do not keep program level records of the methods supplied at a client visit for the methods supplied by the CBD agents. Thus, only UMATI and SDA could be compared on their method mix for methods supplied by the CBD agents. Figure 2 indicates that:

- Both UMATI and SDA have a low volume of client visits per CBD for spermicides.

- SDA agents have many more pill client contacts per CBD than for condom users. This may be because condom use tends to be associated with extra-marital sex by the SDA church. UMATI also has more pill client contacts than condom ones, but the difference between them is not nearly as large as for SDA.

- Table II.4 indicates that SDA has the highest and UMATI the lowest referral client contacts per CBD.

- For the three programs, injectable client contacts account for the highest referral client contacts per CBD. Only SDA agents refer a significant number of clients for other referral methods. 
FIGURE 2

AVERAGE CLIENT VISITS PER CBD AGENT BY PROGRAM AND METHOD

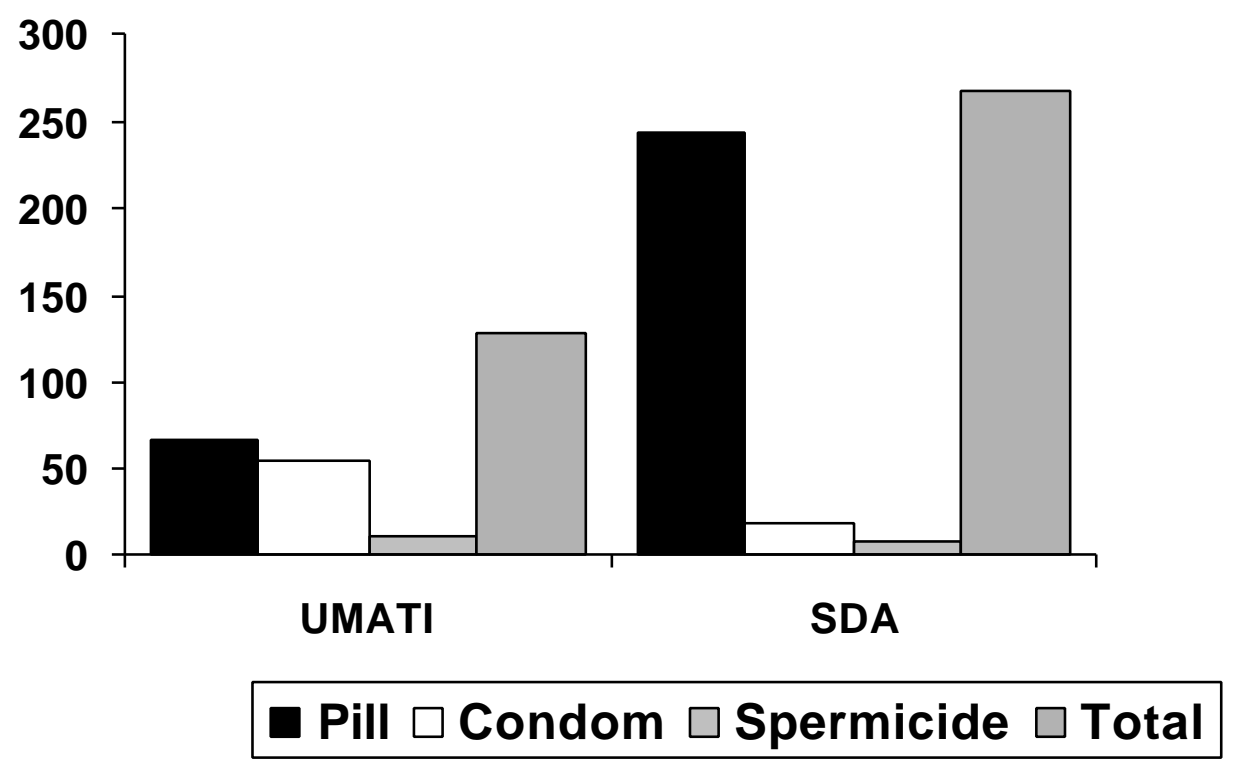

Table II.4 Average Annual Client Visits per CBD Agent for Referrals (based on data from $1995 \& 1996$ )

\begin{tabular}{|l|c|c|c|c|c|c|}
\hline Referral method visit & \multicolumn{2}{|c|}{ SDA } & \multicolumn{2}{c|}{ UMATI } & \multicolumn{2}{c|}{ FPU } \\
\hline & Referrals & \% & Referrals & \% & Referrals & \% \\
\hline Pill & 26.2 & 17 & 0.3 & 8 & 0.1 & 1 \\
\hline Injectables & 66.8 & 42 & 1.7 & 47 & 4.8 & 90 \\
\hline IUCD & 10.8 & 7 & 0.3 & 8 & 0.1 & 2 \\
\hline NORPLANT® & 15.4 & 10 & 0.2 & 6 & 0 & 0 \\
\hline VSC $^{\text {Non-FP services }}{ }^{\mathbf{1 5}}$ & 5.9 & 4 & 0.5 & 12 & 0.1 & 2 \\
\hline Total & 32.8 & 21 & 0.7 & 19 & 0.3 & 5 \\
\hline
\end{tabular}

15 For example for MCH and STD/HIV services and treatment of illnesses). 


\subsubsection{Average CYP generated Per CBD agent}

Figure 3 and Table II.5 present the average CYP per CBD generated through methods supplied by $\mathrm{CBD}$ agents and referrals ${ }^{16}$ respectively. Figure 3 shows that:

- All programs generate most of their CYP through pill distribution. The use of spermicides, particularly, is quite low.

- However, there are differences between the proportion of pill and condom CYP per CBD in the different programs. SDA and MOH Zanzibar are predominantly pill programs and pill CYP per CBD is almost ten times higher than CYP generated through condom distribution. In contrast, FPU and UMATI generate two-thirds of their CYP through pill and one-third through condom distribution.

- Although SDA had the second highest volume of client contacts for methods supplied by CBD agents, this program has the highest volume of CYP per CBD for methods supplied by CBD agents. The reason for this difference relates to differences in the volume of methods supplied to a client at each visit and also the method mix. SDA provides more pill cycles per visit than the other programs. In addition, SDA is a pill-focused program compared to UMATI, which has a significantly high number of condom client visits. One pill visit generates higher CYP than one condom visit.

16 CYP conversion factors are the 1991 values recommended by the USAID Cooperating Agency Task Force on Program Performance Indicators (PPI). For pills, 15 cycles $=1 \mathrm{CYP}$ and for condoms and vaginal foaming tablets 150 pieces $=1 \mathrm{CYP}$. 


\section{FIGURE 3}

AVERAGE CYP PER CBD AGENT GENERATED BY METHOD DISTRIBUTED

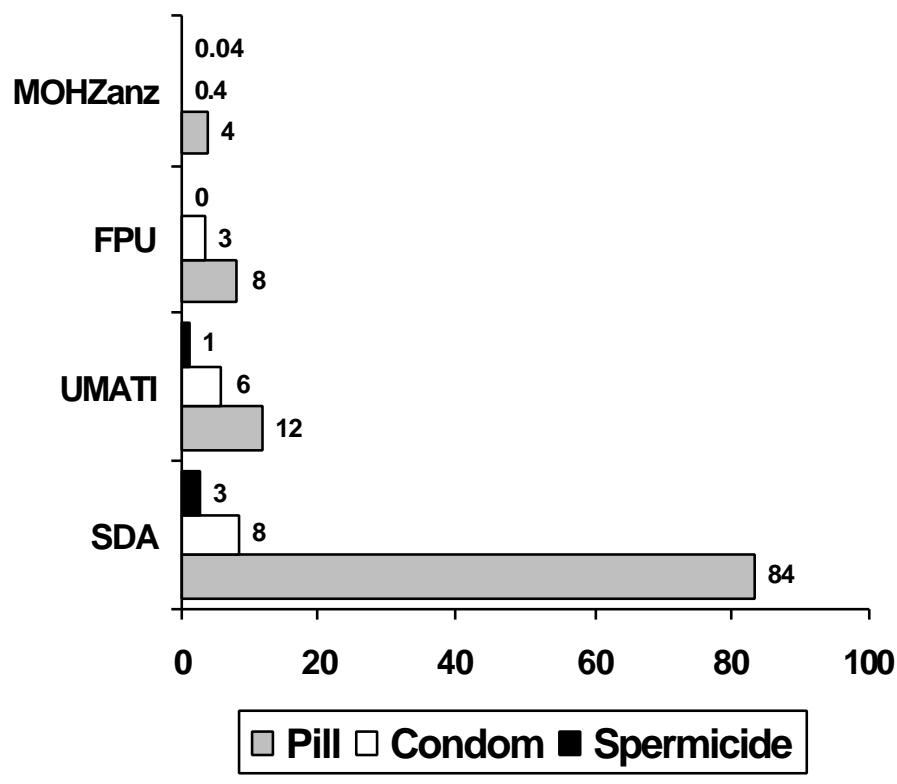


Table II.5 reveals that:

- As 90 percent of referrals by FPU CBD agents are for injectables, it is not surprising that injectables account for nearly one-half of all their referral CYP per CBD. In contrast, injectables account for less than 10 percent of referral CYP per CBD for SDA and UMATI.

- Due to the high CYP generated through one surgical contraceptive operation, this referral method generates the highest CYP per CBD for SDA and second highest for FPU.

- The average CYP per CBD generated through methods supplied by the CBD agents is greater than that generated from referral methods for all the programs except SDA. Thus, in most areas, CBD agents have their greatest impact as a source of supply for non-clinical rather than referral methods.

Table II.5 Average Annual CYP Per CBD Generated by Referrals

\begin{tabular}{|l|c|c|c|c|}
\hline & SDA & UMATI & FPU & MOH Zanzibar \\
\hline Pill & 1.8 & 0.002 & 0.005 & 0.04 \\
\hline Injectables & 16.7 & 0.4 & 1.2 & 0.8 \\
\hline IUCD & 37.7 & 1 & 0.4 & 1 \\
\hline NORPLANT® & 53.9 & 0.8 & 0 & 0 \\
\hline VSC & 70.2 & 5.4 & 1.1 & 0.2 \\
\hline Total & 180.4 & 7.7 & 2.6 & 2.1 \\
\hline
\end{tabular}




\section{FACTORS ACCOUNTING FOR VARIANCE IN PROGRAM PERFORMANCE}

The analysis of program performance based on CBD outputs in the previous chapter clearly indicates that agents provided with a monthly allowance (SDA) perform better than those provided with non-monetary incentives (UMATI, FPU). In addition, the programs providing their agents with some non-monetary incentives perform better than the program that does not provide any incentives (MOH Zanzibar). However, due to the many differences between these programs described in Chapter 1, we cannot attribute the variance in output wholly to the impact of remuneration.

It is difficult to control all the factors that might impact on output. This chapter attempts to investigate the impact of a number of factors, which other studies of CBD programs have found to contribute to program performance. ${ }^{17}$ The factors to be investigated are individual agent's characteristics, demand for family planning, the range of services provided by agents, supervision and management, and the impact of remuneration on job satisfaction. The data for this section is culled from Focus Group Discussions with CBD agents, in-depth interviews with the immediate CBD supervisors, and review of CBD program records in each selected district.

\section{III.1 Sex of Agent}

The analysis of differences in output according to characteristics of the agent focuses on differences according to the sex of the agent. Only the sex of the agent is examined for several reasons: 1) Apart from the $\mathrm{MOH}$ Zanzibar, the sampled CBD programs do not vary significantly in their selection criteria except in $\operatorname{sex}^{18} ; 2$ ) a comparison of CBD programs in Kenya found that age, marital status, and education made very little difference to CBD agents' productivity ${ }^{19}$; and 3) the individual performance records needed to analyze the relationship between agent characteristics and output only contain information on sex.

See Jane Chege and Ian Askew. 1997. An Assessment of Community-Based Family Planning Programs in Kenya. The Population Council, Africa Operations Research and Technical Assistance Project II publication. See also Findings From Phase 1 of the Navrongo Community Health and Family Planning Project. In Update 1996, No.5, The Population Council, Africa Operations Research and Technical Assistance Project II.

18 The selection criteria followed by the three programs are:

a) Education: Minimum of seven years of schooling

b) Volunteerism: Be willing to provide volunteer services (except for SDA)

c) Residence: Be a permanent resident of the catchment area

d) Age: Not less than 18 years

e) Interpersonal relations: Be of good repute and acceptable in the community

f) Marital status: Preferably married

g) Sex: Both the FPU and UMATI programs lay emphasis on recruiting both male and female CBD agents, in equal proportions if possible, while SDA has very few male CBD agents.

h)

19 See Chege J.N. and Ian Askew, 1997. 
An analysis of the impact of the sex of the agent on their output was undertaken using individual CBD output records from two FPU districts (Mufindi, Igunga) and three UMATI districts (Iringa, Hai, Moshi). As seen in Table III.1 the analysis reveals that:

- female CBD agents are more active than male agents in providing FP services to their communities;

- are as good as their male counterparts in distributing condoms and referring clients for clinical methods. Although male agents distribute more condoms, the difference between them and the female agents is not significant

- see significantly more pill clients and generate more CYP from pills compared to the male agents;

- overall, see more clients and generate more CYP for all the methods supplied by CBD agents (because of the greater volume of pill visits and distribution).

\section{Table III.1 Comparison of Mean Outputs per Agent by Sex of Agent (1995)}

\begin{tabular}{|l|c|c|}
\hline & Male $(\mathbf{n = 2 3 4})$ & Female $(\mathbf{n}=\mathbf{2 4 6})$ \\
\hline \# of condom clients & 46 & 44 \\
\hline Condom CYP & 4.9 & 4.5 \\
\hline \# of pill clients* & 43 & 62 \\
\hline Pill CYP* & 7 & 11 \\
\hline \# of supply clients & 97 & 115 \\
\hline Supply CYP* & 13 & 17 \\
\hline \# of referral clients & 4 & 4 \\
\hline Referral CYP & 1 & 1 \\
\hline
\end{tabular}

* $\quad$ Statistically significant difference

\section{III.2 Range of Activities Undertaken and Services Provided by CBD Agents}

The sample CBD programs vary in the range of activities and services provided by their CBD agents. Agents from all the programs do the following: 
- Use person to person approach through visiting households to reach their clients

- Provide family planning IEC

- Recruit new clients, supply and re-supply pills, condoms \& spermicides to clients

- Refer for clinical methods

- Keep records of clients served by method and contraceptive dispensed

- Follow-up on FP referrals at the clinic

- Follow-up on FP dropouts.

Additionally, UMATI and FPU agents provide MCH referral services, while SDA agents provide both STI/HIV and MCH information and referral services. The MOH Zanzibar program focuses mainly on FP services. The output for these activities has been included in this analysis. ${ }^{20}$ Thus, the UMATI program has the widest range of services provided followed by SDA while MOH Zanzibar has the narrowest range.

The variation in the range of activities and services provided by $\mathrm{CBD}$ agents is expected to affect FP output per CBD agent. One of the arguments raised against integration of FP services with a wider range of reproductive and other community health services is that this is likely to detract from the quantity (and quality) of FP services which CBD agents can provide. The findings of this analysis, however, do not support this argument. Agents providing integrated services have higher FP outputs per agent than those providing FP services only.

- Firstly, a comparison of program output per CBD agent indicates that the UMATI program, whose agents provide a wider range of services than the FPU and $\mathrm{MOH}$ Zanzibar, have higher FP outputs per CBD than these two programs. The three programs all rely on volunteer parttime CBD agents. However, they vary in their supervision structures and practices and in the non-monetary incentives received by the agents.

- Secondly, a comparison of performance of agents from the same program but having variation in the range of services they provide confirm the fact that the observed difference in performance may not be due to variations in supervision and motivation. Currently, UMATI has two ${ }^{21} \mathrm{CBD}$ approaches that differ in the activities they undertake. These are the Integrated Project (IP) approach in Hai, Moshi rural, Morogoro rural, and Magu districts, and the Free Standing approach in Iringa rural district. In addition to the activities and services provided by the free standing agents, the IP agents have IGA activities and provide parasite control services. As Table III. 2 shows, the output per CBD agent for all the IP sites is higher than that of the free standing Iringa rural site.

The programs also provide the following services that are not included in this analysis: UMATI, FPU, and SDA provide education and motivation during small group and public meetings; SDA and some UMATI agents provide services and IEC at the clinic; UMATI, FPU and SDA agents conduct community census of their individual catchment areas every year; and UMATI agents provide safe motherhood and nutrition education, parasite control (de-worming and educating the community about environmental sanitation), and education on construction of and quarterly census on ventilated improved pit (VIP) latrines.

21 In 1997, UMATI developed and began implementation of a third approach, the Clinic linked (Vision 2000) in 2 wards in Dodoma urban, all sisal plantation sites in Tanga region, Engale-Olmotony ward in Arusha region, 12 wards in Mtwara and in Songea urban. 
Table III.2

Number of Client Visits and CYP per CBD Agent for the Freestanding and Integrated Sites for the UMATI Program

\begin{tabular}{|c|c|c|}
\hline & Client Visits & $\begin{array}{c}\text { CBD-supply method } \\
\text { CYP }\end{array}$ \\
\hline \multicolumn{3}{|c|}{ Integrated Approach Sites } \\
\hline Hai & 145 & 19 \\
\hline Moshi & 144 & 22 \\
\hline Morogoro & 152 & 20 \\
\hline \multicolumn{3}{|c|}{ Free Standing Approach Site } \\
\hline Iringa Rural & 110 & 18 \\
\hline
\end{tabular}

- Further, a comparison of output per agent for those in the Iringa rural site indicates no significant difference between agents providing FP services only, and those integrating FP with other health services. One group of the Iringa CBD agents provides only FP services in Kalenga and Mazombe wards. Another group of UMATI agents provide FP and growth monitoring ${ }^{22}$ services in Ismani, Pawaga and Mlolo wards of Iringa rural district. In 1996, while the site providing FP service only had 94 and 17 client visits and CYP per CBD respectively, the agents providing growth monitoring services had 93 and 15 client visits and CYP per CBD respectively.

- These trends in output are supported by information collected through focus group discussions. CBD agents reported that offering a wider range of services provides them with a better standing in their communities. Agents not providing MCH and STD/HIV information and referral services expressed a need to receive training for a broader range of services. They pointed out that their community members ask them questions and request services beyond family planning.

\section{III.3 Environment of Demand for FP}

"I face great challenges when educating group. The Roman Catholic leaders oppose my activities, they say pills cause cancer and that condoms are porous and will cause them to be infected with HIV. This is the greatest hindrance to CBD work and affects the recruitment of new clients." (UMATI agent from Iringa rural district)

One would expect that all other factors being equal, CBD agents providing services in urban areas would have better performance than their counterparts operating in the rural areas. Urban areas have higher population density, which means less travel time and a higher potential client base compared to rural areas. In addition, urban-based agents and agents operating in high CPR sites are more likely to find clients willing to receive their services because of the higher demand for FP in

22 Weighing and measuring height of children at the clinic. 
these areas. Further, as seen in the quotation above, in areas where there are socio-cultural factors that negatively affect FP acceptance and demand, the CBD output is expected to be low.

\section{(a) Urban and rural differences}

To assess the impact of an urban location on CBD output, the performance of the SDA agents working in the Urban district of Zanzibar and in Musoma was compared to that of the $\mathrm{MOH}$ Zanzibar agents working in the same district in Zanzibar as well as the FPU urban site in Tabora municipality. The analysis indicates that the high SDA output cannot be wholly attributed to the fact that SDA agents operate in urban areas. As table III.3 shows:

- SDA agents' output per CBD in the Urban district of Zanzibar and Musoma urban area in Tanzania mainland is significantly higher than that of the FPU and the MOH Zanzibar urban sites.

- MOH Zanzibar agents operating in the urban district have a significantly low output compared to SDA agents operating in the same district.

\section{Table III:3 Average Number of Client Visits and CYP per CBD Agent for Comparable} Urban Districts

\begin{tabular}{|l|l|c|c|}
\hline \multicolumn{1}{|c|}{ Program } & \multicolumn{1}{c|}{ District } & Visit per CBD & CBD-supply CYP \\
\hline SDA & Zanzibar Urban & 434 & 104 \\
\hline MOH Zanzibar & Zanzibar Urban & 29 & 3 \\
\hline SDA & Musoma Urban & 500 & 84 \\
\hline FPU & Tabora Municipality & 96 & 13 \\
\hline
\end{tabular}

While the higher SDA output may be attributed to factors other than demand, which vary among the various programs, one would expect that within the same program, agents operating in urban sites would have higher output than their rural counterparts. A comparison of urban and rural output within the same program however, does not support this view. The performance of urban agents is not significantly higher than the rural-based agents in the same program.

- As Table III.4 and Figure 5 show, the performance of both the FPU and MOH Zanzibar agents based in urban sites is not necessarily better than that of the respective programs' agents located in rural sites. Further, although the MOH Zanzibar urban district site had the highest number of client visits, the three rural districts had slightly higher average CYP per CBD.

- Agents in all of UMATI's rural districts had a higher CYP and client visits per CBD than the agents in FPU and the MOH Zanzibar urban sites (compare tables III.3, III.4 and III.5a \& b). 
Table III.4 Output per CBD Agent in the FPU Program by Districts - 1995

\begin{tabular}{|l|r|c|l|c|c|c|}
\hline \multicolumn{1}{|c|}{ Region } & CPR & $\begin{array}{c}\text { Unmet } \\
\text { need }\end{array}$ & \multicolumn{1}{c|}{ District } & Urban/Rural & Visits & CYP \\
\hline Dodoma & 11.4 & 21.3 & Dodoma & Rural & 256 & 14 \\
\hline Dodoma & 11.4 & 21.3 & Mpwapwa & Rural & 149 & 9 \\
\hline Coast & 23.5 & 16.6 & Kibaha & Rural & 109 & 22 \\
\hline Tabora & 11.1 & 16.7 & Tabora Municipality & Urban & 96 & 12 \\
\hline Tanga & 12.6 & 19.1 & Lushoto & Rural & 82 & 29 \\
\hline Coast & 23.5 & 16.6 & Rufiji & Rural & 62 & 14 \\
\hline Tabora & 11.1 & 16.7 & Igunga & Rural & 60 & 6 \\
\hline Iringa & 7.7 & 14.7 & Mufindi & Rural & 24 & 6 \\
\hline
\end{tabular}

Table III.5a Average Output per CBD Agent by District for MOH Zanzibar Program (1995 \& 1996)

Ugunja Region Districts, CPR = 9.2; Unmet FP need 29.5

\begin{tabular}{|l|l|c|c|}
\hline District & \multicolumn{1}{|c|}{ Urban/Rural } & Visits & CYP \\
\hline Urban & Urban & 29 & 3 \\
\hline West & Rural & 16 & 4 \\
\hline Central & Rural & 8 & 4 \\
\hline South & Rural & 5 & 4 \\
\hline
\end{tabular}

Table III.5b Average Output per CBD Agent by District for UMATI Program (1995 \& 1996)

\begin{tabular}{|l|c|c|l|c|c|c|}
\hline \multicolumn{1}{|c|}{ Region } & CPR & $\begin{array}{c}\text { Unmet FP } \\
\text { Need }\end{array}$ & \multicolumn{1}{|c|}{ District } & Rural/Urban & Visits & CYP \\
\hline Morogoro & 13.3 & 17.2 & Morogoro rural & Rural & 152 & 20 \\
\hline Kilimanjaro & 23.7 & 13.7 & Hai & Rural & 145 & 19 \\
\hline Kilimanjaro & 23.7 & 13.7 & Moshi & Rural & 144 & 22 \\
\hline Iringa & 7.7 & 14.7 & Iringa rural & Rural & 110 & 18 \\
\hline
\end{tabular}




\section{(a) CPR and FP unmet need differences}

Among the rural programs, each program operates in areas that vary in the prevalence of modern method use and in the unmet need for FP. To assess the impact of these factors on CBD agent performance, the output of programs in high, medium and low CPR and FP demand sites was compared. This analysis reveals no clear relation between the CPR and CBD agent output. Agents operating in some high CPR sites perform better than their colleagues in the same program operating in medium or low CPR sites do. However, in other sites, they have lower output than do the agents operating in medium CPR sites. For example, the Hai and Moshi UMATI CBD individual agents' output is lower than that of Morogoro rural district, a medium CPR site. Similarly, the FPU Lushoto district site, a medium CPR district had higher output per CBD than the Coast region districts that have high CPR. However, both the UMATI and FPU agents operating in the low CPR region of Iringa had the lowest output in their programs. Except for Dodoma FPU sites which have high unmet need and high CBD outputs, the analysis on variations in the level of unmet need reveals similar trends as those of the CPR analysis.

\section{(b) Socio-cultural differences}

Factors identified as constraining FP demand and use are rumors about negative side effects of FP, religion, gender relations and cultural value of many children.

- Rumors About side effects of FP. These exist in all areas, although more agents reported this to be a serious issue in Zanzibar and Iringa regions.

- Religion. In areas in Iringa region, where the Roman Catholic religion is predominant, CBD agents face resistance from the church authorities. This makes it quite difficult for agents to influence clients to adopt modern contraceptive methods. Church authorities have threatened to ex-communicate some CBD agents who are Roman Catholics and some agents have dropped out due to religious pressure. While in the mainland Islam is not a strong deterring factor, in Zanzibar agents from both the MOH Zanzibar and the SDA programs reported Islam as a serious factor affecting their ability to promote FP. Some community members in Zanzibar have dubbed SDA agents as "killers of children."

- Gender Relations. Some men will not allow their wives to use modern contraceptive methods because they think that their wives will become promiscuous. Initially, in some areas in Iringa region, there were instances of men resisting male CBD agents serving their wives. However, with more education, this problem has been overcome in the affected areas. It is only in Zanzibar where the SDA and MOH Zanzibar programs have hesitated recruiting male agents due to fear of a cultural backlash and where some men openly resist their wives' use of FP methods. Agents working in mainland Tanzania underscored the fact that there is no problem in male clients serving females or vice-versa. In fact, in a number of cases, agents said that clients prefer to receive FP services from members of the opposite sex. 
- Cultural value of children In some areas in Dodoma, some clans feel they are too small and would like to increase their number. Others just want to have many children. As one FPU agent explained: "amongst the Wagogo for instance, men want their wives to give birth until all the 'eggs' are finished."

A comparison of CBD performance in areas affected by these negative socio-cultural factors suggests that these factors have a negative impact on CBD output. Unfortunately, the data collected in this study do not allow a thorough analysis of the effect of socio-cultural factors on CBD output.

- Both the FPU Mufindi and the UMATI Iringa rural sites in Iringa region, which report serious religious opposition, had the lowest client visits and CYP per CBD agent in their programs. However, the SDA Zanzibar Urban district CBD agents appear to have overcome the cultural barriers of male opposition to spouse's use of FP and the religious opposition to FP use. Compared to the other seven SDA sites, the SDA Zanzibar Urban district site had the third and the fourth highest CYP and client visits per CBD, respectively. Similarly, with the highest and the fourth highest number of client visits and CYP per CBD, respectively, the performance of the FPU Dodoma site agents is better than most FPU sites despite the cultural constraints of a high value of children reported by agents in this area.

- However, it is important to note that there is a correlation between socio-cultural factors affecting demand and use of FP and CPR. The Iringa and Ugunja regions, whose agents reported that socio-cultural factors have a serious impact on their output, also happen to be the areas with low CPR.

Despite the expectation that CPR and socio-cultural factors have an impact on CBD output, these differences do not explain all of the variance in program performance.

\section{III.4 Remuneration and Job Satisfaction}

Provision of monetary incentives to CBD agents is based on the premise that paid agents will be more highly motivated and consequently have lower dropouts and produce higher outputs. However, the findings do not wholly support this notion. Analysis of sentiments expressed by CBD agents regarding their satisfaction with the job they perform and program records on CBD dropouts reveal that:

- Monetary remuneration of CBD agents alone does not guarantee job satisfaction.

- Non-monetary incentives have a significant impact on CBD job satisfaction and motivation.

- Job satisfaction has a higher impact on CBD retention rates than monetary remuneration.

\section{III.4.1 Monetary remuneration and job satisfaction}

In spite of the fact that SDA agents receive a monthly salary, some agents expressed dissatisfaction with their current level of monetary remuneration. They complained that the money they received was too little to meet their family needs. In Zanzibar they said that it did not adequately 
compensate them for all the work they did from 7:30 a.m. to 3:30 p.m. In addition, they said that they had no job security because they were not provided with pension. Nevertheless, the SDA agents said that due to lack of a better alternative, they prefer to do CBD work rather than stay at home and "just rear children."

As full-time workers, SDA CBD agents feel that they ought to be well remunerated and be provided with employment benefits similar to other full-time paid employees. These SDA agents' complaints contrast sharply with sentiments expressed by the volunteer agents. A number of FPU and UMATI agents talked of the need to reconsider CBD voluntary services in view of the difficult economic conditions. Yet they did not have high expectations of benefits that salaried employees enjoy because they accepted the volunteer nature of the job from the time of their recruitment. Furthermore, they have time to undertake their personal business unlike the SDA agents.

\section{III.4.2 Non-monetary incentives}

As discussed in Chapter 1, CBD programs provide non-monetary incentives to their agents so as to increase their level of motivation and job satisfaction. In response to a question on what motivates them in their work, agents mentioned supervision, community recognition and support, and participation in IGAs. The type of non-monetary incentives provided to agents varies within the various programs. UMATI agents expressed the highest level of motivation and job satisfaction due to the non-monetary incentives they received from the program, followed by SDA agents. MOH Zanzibar agents had the lowest level of motivation.

\section{a) Supervision:}

CBD agents who receive monthly individual supervisory contacts express higher motivation than those who do not or receive few individual supervisory contacts in their place of work. Generally, the SDA, UMATI, and FPU agents expressed satisfaction with the level of supervision they received and their relationship with their supervisors. By increasing their confidence and recognition in the community, individual supervisory contacts increase agents' motivation.

One group of agents observed during a group discussion:

"When you have your supervisor and you introduce her to clients, your respect as a CBD goes up. They will trust the supervisor more... You see when you are accompanied by your supervisor during visits to clients, you feel more secure... Even when you are wrong, the supervisor can correct you immediately you are through with the client."

The type of supervisor a program uses (part-time or full-time) coupled with the ratio of CBD agents per supervisor have a bearing on the number of monthly individual supervisory contacts with CBD agents and agent's satisfaction with the supervision received.

The FPU program has the Maternal and Child Health Assistants (MCHAs) and Clinical Officers (COs) as the immediate CBD supervisors. Since these officers provide services at the clinic, only a proportion of their time (approximately 40\%) goes to CBD tasks. Each supervisor 
supervises on average between 2 to 4 CBD agents. The FPU policy is for the immediate CBD supervisors to have one group and two individual supervisory visits each month to CBD agents in their working area.

UMATI relies on part-time volunteers known as CBD leaders. Each CBD leader supervises approximately 10 agents. UMATI supervisors live and work together in the same villages with the agents they supervise. The CBD leaders report to the CBD supervisor or CBD/IP Coordinator who are full-time staff working on the CBD program in each district. UMATI CBD supervisors and coordinators at the regional level meet all the $\mathrm{CBD}$ leaders every month to discuss $\mathrm{CBD}$ performance and receive CBD output records. In addition, UMATI supervisors have quarterly meetings with groups of CBD agents in their area. During these meetings, CBD agents inform their supervisors of any problems regarding individual or group of agents.

In the SDA program, a full-time CBD supervisor has between 15 and 26 CBD agents under his or her supervision. SDA CBD agents report to the clinic every morning before going to their catchment areas and afternoon after completing their daily tasks. They meet their supervisor at the clinic every Friday morning. During these meetings the CBD agents:

- Receive training on various CBD work related topics

- Receive response for problems encountered while providing services over the week

- Receive feedback on IEC topics they plan for groups and on their implementation

- Check on referrals

SDA supervisors also accompany one or two CBD agents a day during their household visits. Ideally, the supervisor is expected to do this three days in a week. Depending on the number of CBD agents in an area, the supervisor is able to make individual supervisory contacts with each $\mathrm{CBD}$ in a month. The SDA policy requires the supervisor to use a checklist to supervise individual agent's performance.

The MOH Zanzibar supervisory structure is not significantly different from that of the FPU. A MCHA is the immediate CBD supervisor, supervising between 2 and 4 agents. The MCHA spends about 20 percent of their time on CBD activities. However, the MOH Zanzibar CBD supervisors appear to have no explicit policy on supervisory meetings with CBD agents that guide their supervision activities. Those agents who are also TBAs have the advantage of meeting their supervisors as a group every Friday at the clinic. During these meetings, TBAs receive teachings on midwifery and discuss CBD matters.

The unevenness of supervision in the $\mathrm{MOH}$ Zanzibar program is clear in the following statements:

"I meet the TBAs every Friday... I teach them midwifery activities... and in addition, CBD activities. We discuss their service problems and if they have shortage of commodities."

"I meet them once a week. They come to the clinic and I train them how to fill re-supply cards."

"I usually follow them after finishing my work in the clinic." 
"Visiting urban people (CBDs) in their homes is a problem ... May be it is best to meet them on the way, away from their homes."

The varying styles of supervision may explain why many MOH Zanzibar agents expressed dissatisfaction with the level of the supervision that they receive.

Although the SDA and UMATI programs have the highest ratio of CBD agents per supervisor, these programs rely on full-time supervisors and have put in place an effective system to ensure constant interaction between CBD agents and their supervisors. The ratio of CBD agents to a supervisor in the FPU program is much lower than the SDA and UMATI programs. However, the structure of the supervision is such that FPU supervisors have fewer opportunities for contact with agents than UMATI (whose CBD "leaders" live in the community) and SDA (who have daily contact and weekly meeting at the clinic).

\section{b) Community Recognition and Participation:}

Agents whose program management and supervision system allow for community support, participation in CBD activities, and recognition of CBD agents are more motivated than those without a community support system. The FPU, SDA, and UMATI programs all encourage some form of community participation in CBD activities:

- FPU and UMATI first undertake a baseline survey and seek community consent and support before implementing the program in a new site. SDA also sensitizes the community before starting service provision in an area.

- All the three programs provide selection criteria to the Ward leaders who short-list the candidates. The short-listed candidates are interviewed by the district program staff and the successful ones are recruited. ${ }^{23}$

- In addition to the oral interview, UMATI and SDA agents complete a written interview.

- The MOH Zanzibar program has minimal community participation in CBD activities. MOH staff stationed at the health centers recruit CBD agents who are either satisfied FP clients or existing Traditional Birth Attendants (TBAs) trained by the Ministry. Although the policy is to have literate agents, a number of recruited TBAs are illiterate.

UMATI and SDA programs not only involve community leaders in recruitment of CBD agents, but also in the day to day running of the program. Community leaders in both programs assist in monitoring CBD activities and seeking solutions to problems CBD agents encounter in providing the services. SDA agents have to register their reporting and ending time with the respective village leader every day they work in the village. The UMATI agents from Hai explained their interaction with community leaders in the following words:

23 Initially, FPU did not interview the selected volunteers. However, the program staff changed this position when they realized that in some cases, the community leaders were not following the criteria and provided unsuitable agents. 
"Even the 'Ten Cell leaders' accompany us when visiting households under their jurisdiction.... Even when they see us at home in the morning, they ask us 'are you not going to work today?' They assist us a lot."

UMATI CBD agents and supervisors have quarterly meetings with Ward leaders to review the progress of CBD work in their respective areas. Consequently, community leaders in UMATI areas feel a sense of ownership of the program and have come up with some community incentives for CBD agents. For example,

- CBD agents have been included in the village health and local steering committees.

- In some areas, the village and ward authorities have exempted CBD agents from participating in compulsory community services scheduled in the villages.

- In other areas, community leaders have provided space for CBD IGAs within the village office building.

The FPU program also encourages its CBD agents to be included in their Village Primary Health Committee. There was consensus among CBD agents in expressing great appreciation for their involvement in community leadership and the recognition accorded to them by their communities. When asked to explain how this community recognition motivated them, one agent from FPU program in Mufindi indicated

"I like this work because it gives me respect and makes me a member of my village Health Committee.

Another agent from UMATI said: "The members of my community think that I am employed and children call me UMATI. Clients are happy and appreciate CBD work."

Another from FPU expressed the following sentiments: "I am happy for being selected and entrusted with Government work”.

\section{c) Participation in Income Generating Activities (IGAs):}

UMATI agents who have program sponsored and supported IGAs identified their participation in IGAs as a significant factor in their motivation and job satisfaction. They feel proud that as a group they own a tractor, truck, or sewing machines used to train girls in their community on dress making. The agents feel that the IGA materials are not only a source of savings for them, but they also offer required services to their communities. This increases their respect in the community.

Due to the good management offered by the UMATI program, agents did not report any squabbles related to the management of the IGAs and the resources acquired from them. ${ }^{24}$

24 The only problem was that some of the items, for example, a truck in Kilimanjaro region was not in working order. 
However, the amount of profit accrued from the IGAs and the direct remuneration individual agents receive from these IGAs is not clear. ${ }^{25}$

FPU trains and encourages CBD agents to start IGAs. However, the program does not provide any funding or management support to CBD IGAs. In some areas, FPU agents have some IGAs and in others though they expressed a desire to participate, they felt that without the program helping them to start off, they found it difficult to manage.

\section{III.4.3 Job Satisfaction and agents drop-out rate}

Contrary to expectation, the SDA program with salaried CBD agents does not have a significantly higher CBD retention rate than the UMATI and FPU programs, which provide nonmonetary incentives to their CBD agents. Using program records on the date individual CBD agents were recruited and for those who have dropped out ${ }^{26}$, the date of their dropping out, a Life Table Survival Analysis of the duration agents in SDA, FPU and $\mathrm{UMATI}^{27}$ work for their respective programs was undertaken. ${ }^{28}$ This analysis shows that:

- The three programs all have high CBD retention rates and UMATI has the highest rate. By April 1997, the UMATI program retained 95\%, SDA 92\%, and FPU 86\% of all the CBD agents recruited from the inception of their respective programs.

- Although there was a difference overall in the level of CBD retention, the difference was significant only between the UMATI and the FPU program. Within the FPU program, one site (Igunga district) had a dropout rate that was much higher than the other FPU sites. When this site was excluded from the analysis, the dropout rate in the other FPU districts did not significantly differ from that of the UMATI and SDA districts.

\section{III.5 Conclusions}

The observed differences in status, remuneration, and supervision and management of CBD agents appear to be associated with the level of agent performance among the four programs. The SDA program, which has the highest frequency of group and individual supervisory contacts and involves community leaders in the supervision of CBD agents, has the highest output per CBD agent.

25 The costs and profits of the IGAs to CBD agents were beyond the scope of this study.

In the FPU and UMATI programs, a volunteer who does little or nothing is formally requested by the program to 'drop out.'

27 The analysis was based on records from the following districts: SDA- Zanzibar urban, Musoma and Arusha; UMATI - Hai, Moshi, Iringa and Morogoro rural districts; FPU - Dodoma, Mpwapwa, Mufindi, Tabora urban and Igunga districts.

The available information on number of CBD agents trained in the Ugunja region up to 1996 and those who were actively distributing contraceptives in this region indicate that a high percentage of the agents are not active. Out of 75 trained, only 32 were distributing contraceptives by 1996. However, it was not possible to undertake a Survival Analysis for this program because records or information on when the "drop-out" CBD agents stopped working was not available. 
Among the part-time volunteer and rural-based programs, UMATI, which also involves community leaders in the management and supervision of CBD agents, has the highest output per CBD agent. The FPU program, which has a comparatively lower level of community participation and individual supervisory contacts than both the SDA and UMATI programs has lower output than these programs. The MOH Zanzibar program, which compares poorly with other programs in relation to community participation and volume of individual and group supervisory contacts, has the lowest output per agent. However, it is important to note that remuneration schemes from best to worst have the same order (SDA, UMATI, FPU, MOH Zanzibar).

Thus, no one single factor can explain the variance in programs' output. A combination of factors affects CBD output and contributes to CBD motivation or lack of it. Chief among these is monetary and non-monetary incentives, an effective management and supervision system coupled with strong community support and participation in the CBD activities. These factors override the demand environment factor. In addition, IGAs and non-monetary benefits such as prestige and community recognition accrued from CBD work play a significant role in motivating CBD agents and subsequently affecting their output and job satisfaction. The comparatively high community participation in the management of CBD activities coupled with the IGAs (which benefit not only the CBD agents but in some cases their community members) partly explains the high level of job satisfaction among UMATI CBD agents. Factors that can be said to explain the high output for SDA CBD agents are the time spent on CBD activities and the program's efficient supervision.

The fact that a program has high output does not necessarily guarantee that the program is more cost-effective or vice versa. The next chapter is devoted to an examination of the costeffectiveness of these programs. 


\section{THE COST EFFECTIVENESS OF REIMBURSEMENT SCHEMES}

\section{IV.1 Introduction}

Each of the programs in the study uses a different strategy to remunerate its CBD agents. These strategies are:

(1) Full-time agents (SDA), who are given a salary and in-kind contributions (uniforms, bags, metal boxes, umbrellas, etc.)

(2) Part-time volunteers (FPU) who are given a bicycle allowance and in-kind contributions (bicycles, bags and metal boxes)

(3) Part-time volunteers (UMATI) who are provided with in-kind payments (uniforms, bags, metal boxes, umbrellas, etc.) and equipment to share for income generating activities (a boat, tractors, milling machines).

The CBD programs included in our analysis differed in a number of other ways unrelated to remuneration polices including the following: (1) geographic coverage, (2) characteristics of agents, (3) the range of services provided, (4) the supervisory system, and (5) training strategies for agents and supervisors. Table IV.1 summarizes the main characteristics of UMATI, FPU, and SDA that are pertinent to the analysis in this chapter; these factors have been discussed in some detail in earlier chapters. The methods section of this chapter explains how some of these factors were controlled for in the analysis while the concluding section discusses the limitations of our analysis that arise because we were unable to sufficiently control for all intervening factors. 


\section{Table IV.1 Characteristics of CBD Programs Included in this Study}

\begin{tabular}{|c|c|c|c|c|c|c|c|c|c|c|}
\hline Program & Sector & Location & $\begin{array}{c}\text { No. of agents } \\
(1996) / \\
\text { Coverage } \\
\end{array}$ & $\begin{array}{c}\text { CBD Status/ } \\
\text { Remuneration }\end{array}$ & $\begin{array}{c}\text { Agent } \\
\text { Recruitment }\end{array}$ & $\begin{array}{l}\text { Range of } \\
\text { Services } \\
\text { Provided }\end{array}$ & Supervision & $\begin{array}{c}\text { Ratio of Agents } \\
\text { to Supervisors } \\
(1996)\end{array}$ & $\begin{array}{c}\text { Agent } \\
\text { Training }\end{array}$ & $\begin{array}{c}\text { Supervisor } \\
\text { Training }\end{array}$ \\
\hline UMATI & NGO & Rural & $\begin{array}{c}683 / 5 \text { Regions, } \\
6 \text { districts }\end{array}$ & $\begin{array}{c}\text { Volunteer/ } \\
\text { Incentives/ } \\
\text { Income generating } \\
\text { activities } \\
\end{array}$ & Male \& Female & $\begin{array}{l}\mathrm{FP}, \mathrm{MCH}, \\
\mathrm{PHC}\end{array}$ & $\begin{array}{c}\text { Part-time' } \\
\text { provided by CBD } \\
\text { agents }\end{array}$ & $10: 1$ & $\begin{array}{l}\text { Initial and } \\
\text { refresher }\end{array}$ & $\begin{array}{l}\text { Initial } \\
\text { training/No } \\
\text { refresher }\end{array}$ \\
\hline FPU & Public & $\begin{array}{c}\text { Rural \& } \\
\text { Urban }\end{array}$ & $\begin{array}{c}663 / 5 \text { Regions, } 1 \\
\text { urban \& } 9 \text { rural } \\
\text { districts } \\
\end{array}$ & $\begin{array}{c}\text { Volunteer/ } \\
\text { incentives/ allowance }\end{array}$ & Male \& Female & FP & $\begin{array}{l}\text { Part-time/ } \\
\text { provided by } \\
\text { salaried staff } \\
\end{array}$ & $6.4: 1^{*}$ & $\begin{array}{l}\text { Initial and } \\
\text { refresher }\end{array}$ & $\begin{array}{c}\text { Initial } \\
\text { and refresher }\end{array}$ \\
\hline SDA & $\begin{array}{c}\text { Church- } \\
\text { based } \\
\text { NGO } \\
\end{array}$ & Urban & $\begin{array}{c}\text { 189/5 Regions, } 6 \\
\text { urban districts }\end{array}$ & $\begin{array}{l}\text { Monthly salary/ } \\
\text { incentives }\end{array}$ & $\begin{array}{l}\text { Almost all } \\
\text { Female }\end{array}$ & $\begin{array}{l}\text { FP,MCH, } \\
\text { PHC }\end{array}$ & $\begin{array}{c}\text { Full-time/ } \\
\text { provided by } \\
\text { salaried staff } \\
\end{array}$ & $16: 1$ & $\begin{array}{l}\text { Initial and } \\
\text { refresher }\end{array}$ & $\begin{array}{c}\text { Initial } \\
\text { training/No } \\
\text { refresher } \\
\end{array}$ \\
\hline
\end{tabular}

* Ratio based on the number of supervisors as full-time equivalents in 1995 


\section{IV.2 Methods}

A cost effectiveness measure includes costs in the numerator and output or outcome in the denominator. Since the objective is to isolate the impact of reimbursement on the performance of agents, we sought to include only costs related solely to reimbursement and to exclude other costs. Likewise we attempted to select an output measure that would be strongly influenced by remuneration, and rejected other output measures that appeared to be substantially influenced by factors other than remuneration. This first section discusses the measures of costs and outputs used in the analysis while the following section discusses how the data was collected.

\section{A. Selection of Variables for the Cost Effectiveness Analysis}

\section{Output measure}

The goal of this analysis is to evaluate the impact of remuneration on work performance to make recommendations to programs for improving performance through changes in remuneration strategies. The selected output variable should thus reflect activity of the CBD agent that is affected by remuneration but not activity that is affected by other aspects of the job environment including the demand for services and other policies of the program that affect service provision. Our selected variable is the sum of visits to either provide a method or to make a referral. Although this is not the ideal variable, it is the best measure available from CBD records for all three programs. In this section, we discuss our choice of variable and its limitations.

The hypothesis is that remuneration encourages workers to spend more hours on the job and thus to produce more visits, that is, make contact with a greater number of potential clients; thus, the optimum output variable is the average number of visits per agent in some given period of time. Of course, CBD agents produce many different types of visits including those in which they provide methods, make referrals, and still others in which they attempt to motivate women to accept family planning services. This latter category includes both contacts in which women do and do not accept methods. The goal of any program is to increase those visits or contacts in which new acceptors are recruited, continuing users are re-supplied, or referred clients actually visit a clinic. Whether visits prove "successful" is thus affected by both the effort made by the worker and the interest of the potential client, and thus by demand factors which are unlikely to be related to remuneration.

Although visits or contacts are not homogeneous, a single aggregate measure that best represents agent activity is the total number of visits or contacts made with potential clients. However, only one of the three programs (SDA) provided information on the total number of visits or contacts made per agent. Consequently, we were forced to use a somewhat less satisfactory index of work performance based on the number of visits in which a client was provided with contraceptives or was referred to a clinic for family planning (referrals for other than family planning were excluded from the analysis). This output measure may be affected by demand side factors; thus, the impact of remuneration on work performance may be somewhat obscured.

The average number of visits made by female distributors is higher than that for male distributors. To control for differences in output that arise from varying program policies regarding 
the sex of the agent that they deploy, we adjusted the visit variable to control for the sex distribution of agents. We calculated an adjusted number of visits using data presented earlier in this report to determine the number of visits under the assumption that all agents were female.

While it might seem appropriate to use CYPs as the measure of output, upon reflection, this turns out to be a poor choice as this measure is affected by both demand and supply factors that are independent of remuneration. On the demand side, the number of CYPs produced by an agent will depend on the communities' interest in using contraception which, in turn, is linked to population characteristics of the area served by the program.

As discussed above, our selected measure also is affected by demand side factors; however, the CYP measure has an additional drawback in that it is affected by supply side concerns, which are unrelated to remuneration, as well. These include variations by program in the numbers of pills and condoms distributed on an average visit and the method mix. Programs in Tanzania have different policies regarding the number of pill cycles and condoms that are distributed during initial and follow-up visits. A program that distributes a greater amount of any method per visit may produce more CYPs and therefore may appear to be more cost effective but for reasons unrelated to remuneration. Another supply issue concerns the method mix. SDA provides mainly pills while the other two programs provide a substantial number of condoms in addition to pills. One reason for this difference may be that the ratio of male to female agents varies, with males tending to provide more condoms and females more pills. These variations in the mix of methods distributed by each program are also associated with differences in the CYPs of programs.

\section{Cost measures}

On the cost side, the cost measure should include those cost categories affected by reimbursement, while excluding other costs. For example, contraceptive commodity costs are not included because they are independent of how distributors are paid. Administrative costs of the home offices of each of the organizations were also excluded as these were thought to be largely unrelated to remuneration policies. The cost categories that are included in this analysis and the reasons for including them are discussed below:

a) The reimbursement paid to the agent and all other expenses associated with the agent's work functions such as transportation allowances. If the agent is paid in-kind, then the monetary equivalent of those items is treated as reimbursement. If these items are capital goods, that is, they are expected to last more than a year, then these costs are annualized. (This procedure is described below.)

b) The salaries of staff that supervise agents and, if appropriate, the salaries of higher level supervisors. At first glance, it may not seem apparent that it is necessary to consider these costs. However, consider the following hypothetical example: the ratio of agents to supervisors is the same for all programs while visits are positively correlated with agent payment. Consequently, the salary cost of supervisors per visit produced will be lower in those programs in which agents are paid more. Thus, supervision costs cannot be ignored.

c) The training costs for both agents and supervisors. Reimbursement can affect the cost effectiveness of training in two ways. Theoretically, agents who are not paid may be more likely 
to seek other employment. Therefore the costs of training are spread over a shorter time period than are those for paid distributors who may be more content to stay in the program and therefore spend more years working as agents. Second, as discussed above, the output or visits produced by agents may be greater if they are paid; consequently training costs are divided by a larger output for trained paid than for trained unpaid agents even if agents are employed for the same length of time. Thus, training costs must also be taken into consideration in the analysis.

Since all three programs are relatively new, it is difficult to determine the impact of remuneration on agent retention rates. Information available indicates that retention rates are very high (see Chapter III). However, in programs in which agents are not salaried, work performance may simply decline with no formal resignation. Unfortunately, no information exists on how agent performance changes over time. Thus, our consideration of training costs does not adjust for changes in work performance so that the time period over which training costs are amortized does not vary by program.

\section{B. Description of How Variables Were Obtained}

\section{Output measure}

Average annual output per agent is based on results for 1995 and 1996. Data on visits were obtained from 1995 and 1996 service records at the headquarters of each program. ${ }^{29}$ The annual amount of visits produced by each program was divided by the number of active agents in the same reference period to calculate the annual output per agent. ${ }^{30}$

\section{Cost measures}

This section describes how the variables selected for the cost analysis were measured. ${ }^{31}$ The average annual cost per agent was determined using the 1995 and 1996 results. Cost data was obtained from program managers and accounts for the years 1995 to $1996{ }^{32}$ This information was divided by the number of agents working in each year to calculate the annual cost per agent. The costs obtained included both the donor and the program ${ }^{33}$ contribution.

29 As noted in Chapter II, output data for the total FPU program were not available for 1996. Therefore, only 1995 data from that program were used in the cost analysis.

30 The annual number of CBD agents was adjusted to account for those agents who did not work for the entire year. These agents include drop-outs and those who received their initial training during, and not at the beginning, of the year.

The MOH Zanzibar program was excluded from the cost analysis due to the lack of output records for all the CBD agents. The available cost records for this program contained the cost of training and supervising the CBD agents both in Ugunja and Pemba. However, only Ugunja output records were available.

32 Only 1995 cost data was used to make calculations for FPU.

33 For the FPU program, the supervisors' salary cost, which account for more than 50 percent of the total program cost, is paid for by the government. 


\section{a) Payments to CBD agents}

\section{- Direct payments}

SDA was the only CBD program to pay a salary to its agents. Records from the personnel department of the SDA were used to obtain information on salaries paid to the agents. The FPU provided a small allowance to some of its agents for bicycle maintenance. In both programs, the total amount disbursed was divided by the number of agents to determine the direct payment per agent.

\section{- In-kind contributions}

The SDA, FPU and UMATI programs made different types of in-kind contributions to its agents as discussed earlier. Each of these contributions can be classified as a capital good. Capital goods provide services over a period longer than one year. To make costs comparable with those items that are used up in a year, the cost of capital goods must be annualized or spread over the useful life of the item. ${ }^{34}$ The total annual cost was divided by the number of distributors in each program to determine the in-kind contribution cost per agent. ${ }^{35}$

\section{b) Payments to supervisors per CBD agent}

Each CBD program has two types of supervisors. The immediate supervisors are responsible for regularly checking on agents while the upper-level supervisors generally are responsible for managing the immediate supervisors. Payments to supervisors include the salary and benefits plus travel allowances for time spent on field visits. Supervisors who travel by vehicle incur transportation costs. In the UMATI program, selected CBD agents worked as immediate supervisors. To facilitate the analysis, we treated all supervision costs incurred by these agents as payments to CBD agents. These include travel costs and the cost to train agents selected to be supervisors.

\section{- Salaries and benefits}

Information was obtained from program managers on the salaries and benefits paid to immediate and upper-level CBD supervisors. Many of the supervisors have additional duties that are not related to CBD activities, therefore it would not be appropriate to charge all of their remuneration to

To annualize the cost of in-kind contributions we used the following approach. First, we established the purchase price of each item. It would have been too time consuming to review purchase records, therefore we estimated the price to replace each type of item. Second, we estimated the useful life of each item based on interviews with program managers. Books, bags, metal boxes and uniforms were estimated to last 2 years, bicycles for 5 years and heavy equipment and boats for 7 years. Next, we determined what the program could have earned if it had invested the funds used to purchase the item. This component is called the "opportunity cost of capital." We estimated that funds, conservatively invested, would have earned approximately five percent per annum. Using this information we determined the annual cost of each type of in-kind contribution.

35 Each CBD agent in the FPU and SDA typically received the same in-kind contributions. However, agents in the UMATI program received different items depending on the district in which they worked. Therefore, the annual cost per CBD agent for this program was weighted according to the number of agents in each district. 
the CBD program. To address this problem, we interviewed supervisors in a sample of two districts in each program and asked them to estimate the percentage of time they spend per week on CBD activities. We used this information to allocate salary and benefits costs to the CBD program. The annual cost of CBD supervision was divided by the number of agents to determine the salaries and benefits cost per agent.

$\begin{array}{lll} & \text { Immediate } & \text { Upper-level } \\ \text { Program } & \text { Supervisors } & \text { Supervisors } \\ \text { FPU } & 40 \% & 10 \% \\ \text { SDA } & 90 \% & 50 \% \\ \text { UMATI } & \text { N/A } & 100 \%\end{array}$

\section{- Travel costs}

In each program the upper level CBD supervisors are provided with vehicles and travel allowances for transportation to meet the immediate CBD supervisors. The programs do not support transportation used by the immediate CBD supervisors. We measured the following costs associated with supervisor transportation: per diem expenses allocated to the supervisors and vehicle operating costs. ${ }^{36}$ The sum of these costs was divided by the number of CBD agents to calculate the supervisor transportation cost per agent.

\section{c) Training costs per agent and supervisor}

Information on the cost of each seminar and the number of agents trained was obtained from program expenditure accounts. ${ }^{37}$ Using this information the average training cost per agent was determined. Since the benefits of the training seminars last longer than one year, these costs were annualized. ${ }^{38}$ The cost to train the immediate supervisors was divided by the number of agents to determine the supervisor training cost per agent. All programs use either personnel from FPU or

$36 \quad$ Vehicle operating costs include the cost of fuel, maintenance and repair, insurance, and licenses. In most of the programs, use of the vehicles was shared among CBD and other activities. Therefore, vehicle-operating costs were allocated to the CBD program using estimates from program managers on the percentage of time that vehicles were used for CBD supervision. The cost of the vehicles was not measured due to lack of available information from some of the programs. In addition, the labor cost of the drivers was not included due to lack of available information.

37 Expenditure information was obtained for all training sessions held between 1993 and 1996 in order to determine the average training cost per agent.

The costs of the refresher training sessions were annualized over a two-year period. It was more difficult to determine the useful life of the initial training sessions, which should equal the number of years that the agents and immediate supervisors are expected to work in their current jobs. However, an analysis of agent retention rates using life-tables showed that very few of the agents in each program quit working, although some of them may have substantially cut back on work activity. Because a full analysis of the impact of training on job performance was well beyond the scope of this project, we decided to investigate the impact of training under some simplifying assumptions. Thus, we conducted a sensitivity analysis of the effect of annualizing the cost of the initial training over 5, 10 and 20 year periods. The results are provided in Appendix 1. 
their own staff to carry out training sessions, but the costs of these staff are not available and are excluded from the analysis.

\section{IV.3 Results}

\section{A. Output per agent}

Table IV.2 shows average annual visits per program and per agent for the three programs for 1995-96. Column 3 shows the actual visits per agent while column 4 adjusts the visits for gender. ${ }^{39}$ Not unexpectedly, visits per agent are far higher in the SDA program in which agents are full-time, salaried workers than in the other two programs. Because FPU and UMATI have both male and female agents, their adjusted visits are higher than are the actual visits per agent but this difference is not large.

\section{Table IV.2 Average Annual Visits per CBD Agent by Program for 1995-96}

\begin{tabular}{|l|c|c|c|c|}
\hline Program & $\begin{array}{c}\text { Average } \\
\text { Annual Visits } \\
\text { Produced } \\
(\mathbf{1})\end{array}$ & $\begin{array}{c}\text { Average } \\
\text { Annual Number } \\
\text { of } \\
\text { CBD Agents } \\
(\mathbf{2})\end{array}$ & $\begin{array}{c}\text { Average Annual } \\
\text { Visits per Agent } \\
\text { (Actual) } \\
\mathbf{( 3 )}\end{array}$ & $\begin{array}{c}\text { Average Annual } \\
\text { Visits per Agent } \\
\text { (Adjusted)* } \\
\text { (4) }\end{array}$ \\
\hline FPU** & 41,495 & 396 & 105 & 113 \\
\hline SDA & 67,529 & 159 & 425 & 425 \\
\hline UMATI & 65,143 & 494 & 132 & 143 \\
\hline
\end{tabular}

* Adjusted assuming all CBD agents are female ** 1995 only

\section{B. Cost per Agent}

\section{Payments to CBD agents}

Table IV.3 shows the average annual cost per agent by program for 1995-96. The compensation received by agents includes salaries and in-kind payments. For SDA, compensation per agent is nine times higher than for UMATI and about 14 times higher than for FPU.

39 As explained in an earlier chapter, service records show that female distributors make more visits than do male distributors. An adjustment of 8.2 percent was made in the visit measure to control for this variation to eliminate the influence of gender on the output measure. The adjustment was made under the assumption that all the agents in FPU and UMATI were female and that differences in productivity according to gender were the same for each program. 
Table IV.3 Average Annual Cost per CBD agent by program (1995-96) (Tanzanian Shillings)

\begin{tabular}{|c|c|c|c|}
\hline Line Item & FPU* & SDA & UMATI \\
\hline 1. Payment to CBD agents & 17,435 & 223,569 & 24,928 \\
a. Salaries and benefits & - & 191,493 & - \\
b. In-kind payments & 17,435 & 32,079 & 24,928 \\
\hline 2. Payments to supervisors & 112,757 & 134,189 & 18,417 \\
a. Salaries and benefits & 109,930 & 91,939 & 12,268 \\
b. Travel costs & 2,827 & 42,250 & 6,149 \\
\hline 3. Training costs** & 164,537 & 35,708 & 43,965 \\
a. Agent training & 122,388 & 30,998 & 43,965 \\
b. Supervisor training & 42,149 & 4,710 & - \\
\hline Total cost per CBD agent & 294,729 & 393,466 & 87,310 \\
\hline Total cost per CBD agent & 558.20 & 700.74 & 155.49 \\
in US Dollars*** & \multicolumn{3}{|l}{} \\
\hline
\end{tabular}

* 1995 only

** Annualized over ten years

***Based on an average of mid-year exchange rates for 1995 and 1996 (1 US \$ = 561.5 Tanzanian Shillings). 1995 mid-year exchange rate (1US\$ = 528 Tanzanian Shillings)

\section{Payments to supervisors per CBD agent}

Supervision costs per CBD agent include salaries and benefits provided to immediate and upper-level supervisors and travel costs incurred by upper-level supervisors. It turns out that the costs of supervisor salaries per agent are about the same in SDA and in FPU. However, this is because the effects of supervisor salaries and agent to supervisor ratios essentially cancel each other out. Supervisor salaries are higher in SDA than in FPU which, of course, increases the supervisor costs per agent in SDA over those in FPU. However, the ratio of agents to immediate supervisors is lower in SDA so that supervisor costs are spread over a smaller number of agents in FPU than in SDA. Average travel costs per supervisor are highest in SDA and reflect the fact that the area managers travel frequently incurring both high vehicle maintenance costs and travel allowances. This is because they are responsible for a large number of agents. UMATI salaries for supervisor include only those for higher level supervisors since immediate supervisors receive only the same in-kind compensation as agents do.

\section{Training costs for agents and supervisors}

Training costs are far higher for FPU than for SDA and UMATI. Supervisor training costs per agent are highest in FPU for two reasons. First, FPU supervisors spend only 40 percent of their time supervising agents; therefore more supervisors must be trained in order to obtain a coverage rate similar to that in other programs. Second, all three programs initially train both agents and supervisors and provide refresher training to agents; but only FPU provides refresher training for supervisors every two years in seminars and workshops. It is more difficult to explain why agent 
training costs are so much higher in FPU. Although not shown in Table IV.3, the main cost difference is in refresher training. Unlike supervisor training, policies regarding refresher training of the three programs is the same. The differentials in training costs may be explained by some combination of the following factors: possibly higher cost of venues and per diem, or smaller class sizes in FPU than in the other programs.

\section{Total costs}

The last line of the table shows the total costs per CBD agent. Total cost per agent is far lower in UMATI than in the other three programs. In fact, the cost per agent is about one-third less in UMATI than in FPU, even though payments to agents are higher in UMATI than in FPU. Thus, a program such as FPU, which makes only small payments to its agents does not necessarily have low costs per agent. SDA, the program that pays a salary to its agents, has the highest cost per agent, which is 26 per cent higher than in FPU.

\section{Cost effectiveness ratios}

Column 1 of Figure 4 shows the average annual cost effectiveness ratios for the three programs. Costs per visit are lowest in UMATI while they are far higher in FPU. While SDA has the highest output per agent, UMATI has far lower costs per agent so that it also has the most favorable cost effectiveness ratio.

\section{FIGURE 4}

AVERAGE ANNUAL COST (AAC) PER VISIT BY PROGRAM (1995-96) (US\$)

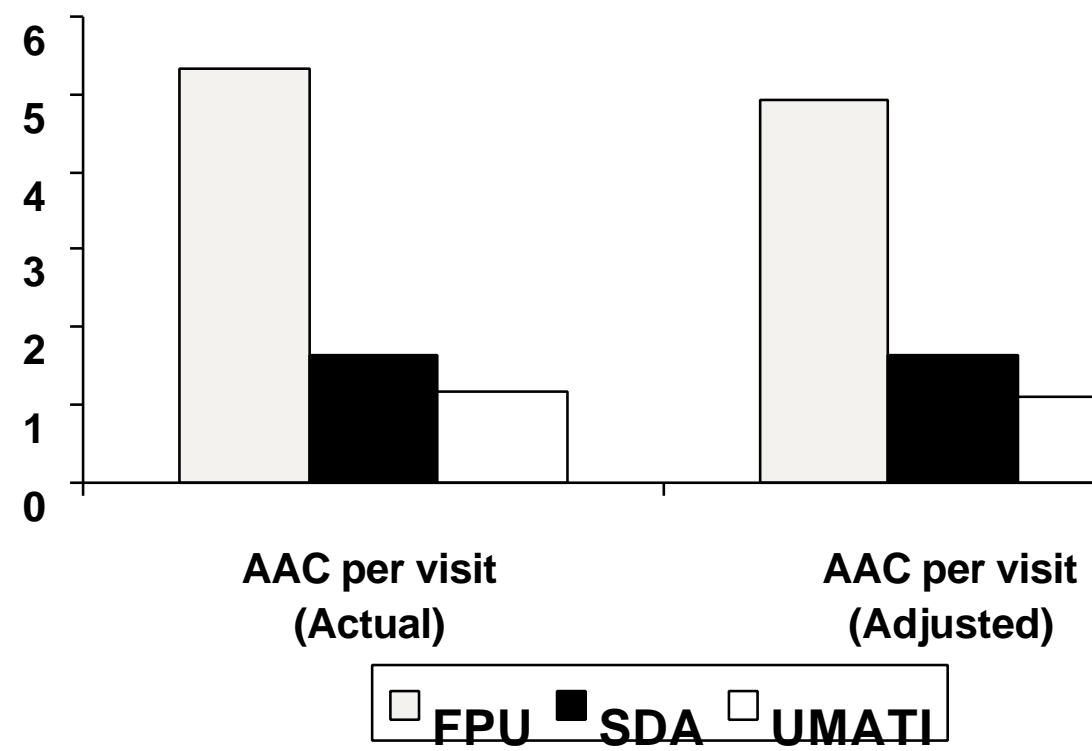


Simulations were carried out to explore how changes in some program variables affected our findings. ${ }^{40}$ In this vein, the second column of Figure 7 shows average annual costs per visit controlling for gender. As expected, this correction makes both the UMATI and the FPU programs look more favorable, but the basic conclusion that UMATI has the most favorable cost effectiveness ratio remains unchanged.

Table IV.4 shows the impact on cost per visit assuming varying budget amounts spent on payments to supervisors and training. Specifically, we examined the impact of large and small amounts spent on these items using data from FPU (high) and UMATI (low). The results in column 1 reveal that if only payments to agents are considered, then FPU appears to have the most cost effective remuneration strategy. However, when supervision and training costs are included, then UMATI is the most cost effective.

Assuming that all three programs spent the same amount per agent as FPU on supervision and training (column 2), SDA has the most favorable cost effectiveness ratio. This is because SDA agents produce the most visits and the high training and supervision costs are divided by a large number of visits.

Assuming that the programs spent the same amount per agent as UMATI on supervision and training, SDA and UMATI are fairly equal in cost effectiveness. When supervision and training costs are low, agent remuneration plays a greater role in affecting cost effectiveness. Thus, although SDA produces a higher number of visits than UMATI, its advantage is negated by its high remuneration costs.

Table IV.4 Cost per Visit by Program and Adjusted Cost per Visit (US \$)

\begin{tabular}{|c|c|c|c|}
\hline \multirow[t]{2}{*}{ Program } & \multirow{2}{*}{$\begin{array}{l}\text { Cost per } \\
\text { Visit* } \\
\text { (1) }\end{array}$} & \multicolumn{2}{|c|}{ Simulated Cost per Visit } \\
\hline & & $\begin{array}{l}\text { Assuming supervision and } \\
\text { training costs for FPU (2) }\end{array}$ & $\begin{array}{l}\text { Assuming supervision and } \\
\text { training costs for UMATI (3) }\end{array}$ \\
\hline $\begin{array}{l}\text { FPU } \\
\text { Payment to agents } \\
\text { Payment to supervisors } \\
\text { and training costs } \\
\text { Total cost per agent }\end{array}$ & $\begin{array}{l}0.29 \\
\frac{4.65}{\mathbf{4 . 9 4}}\end{array}$ & $\begin{array}{l}0.29 \\
\underline{4.65} \\
\mathbf{4 . 9 4}\end{array}$ & $\begin{array}{l}0.29 \\
\underline{0.98} \\
\mathbf{1 . 2 7}\end{array}$ \\
\hline $\begin{array}{l}\text { SDA } \\
\text { Payment to agents } \\
\text { Payment to supervisors } \\
\text { and training costs } \\
\text { Total cost per agent }\end{array}$ & $\begin{array}{l}0.94 \\
\underline{0.71} \\
\mathbf{1 . 6 5}\end{array}$ & $\begin{array}{l}0.94 \\
\frac{1.16}{2.10}\end{array}$ & $\begin{array}{l}0.94 \\
\underline{0.26} \\
\mathbf{1 . 2 0}\end{array}$ \\
\hline $\begin{array}{l}\text { UMATI } \\
\text { Payment to agents } \\
\text { Payment to supervisors } \\
\text { and training costs } \\
\text { Total cost per agent }\end{array}$ & $\begin{array}{l}0.31 \\
\underline{0.78} \\
\mathbf{1 . 0 9}\end{array}$ & $\begin{array}{l}0.31 \\
\underline{3.45} \\
\mathbf{3 . 7 6}\end{array}$ & $\begin{array}{l}0.31 \\
\underline{0.78} \\
\mathbf{1 . 0 9}\end{array}$ \\
\hline
\end{tabular}

* Visits adjusted for gender. 
The important point of this table is that the cost effectiveness of agent remuneration cannot be evaluated by focusing on this variable alone. When supervision and training costs are included in the analysis, UMATI and SDA become more cost effective. This is because they either have low costs for these program functions or they have high outputs over which they divide these costs.

\section{IV.4 Conclusions}

Our findings show that when only payments for agents are considered, FPU is the most cost effective program. However, when other costs per visit, which are affected by remuneration levels are considered, FPU turns out to have the least cost effective remuneration policy. Which of the two other programs then, UMATI or SDA, has the most cost effective remuneration policy? Unfortunately, this question cannot be answered. The two programs spend varying amounts on supervision and training, which presumably boost visit production. An analysis of the simultaneous effects of supervision, training and agent remuneration on visit, production and costs is well beyond the scope of this report. However, our findings do point to some interesting relationships between visits and costs that should be explored.

Concerning visits, although only three programs were analyzed, our findings show that reimbursement was positively associated with the number of agent visits. Although agents in both UMATI and FPU receive only in-kind compensation, the higher payments in UMATI are associated with a greater number of visits per agent than in FPU. In SDA, the program in which agents are paid, visits are far higher. However, we were unable to control for those factors that affect job performance over and above those analyzed in this report. The factors in a program that are hard to measure such as the loyalty of workers and their willingness to work long hours with small rewards can simply not be captured in this kind of analysis.

Turning to costs, these clearly vary in ways that are not associated with remuneration; this is apparent in that the two programs that pay agents in-kind have very different cost structures. This finding suggests that a broad focus should be taken in examining costs of CBD programs. While it is important to examine the impact of remuneration, such a focus may be too narrow. Programs for example, may spend little on remuneration but spend large amounts on training or supervision. The issue is not only how to structure payment policies for agents so as to get the most output per dollar spent on compensation, but also how to allocate the budget for the CBD program among such supporting services such as training and supervision so as to get the most visits or client contacts. Thus, programs that pay little or no compensation might improve their cost effectiveness by spending more on compensation but less on training or supervision. Too narrow a focus on ascertaining the cost effectiveness of remuneration would not enable the researcher to fully understand that financial sustainability might be better served by increasing some costs while decreasing others.

The findings that costs are high in the FPU program and visits are lowest raise questions about the cost structure of the FPU program. Very little of its budget is devoted to compensation of agents, which may be related to the low volume of visits. Instead, FPU devotes a high percentage of its budget to training and supervision, but this strategy may not be justified. Therefore, FPU may want to consider using more of its budget to compensate agents while reducing other costs. 
Our results have important implications for the financial sustainability of CBD programs. In preparing for declines in donor funding, programs need to take a broader focus than simply slashing salaries or payments to agents. The full budget should be examined so as to determine how the program could best survive with lower funding from donors.

If programs are going to learn more about how remuneration affects cost effectiveness, then studies should be conducted that control for program differences not associated with remuneration. Operations research designs are needed because they enable the researcher to control for differences among programs that have plagued this retrospective attempt to study remuneration. Programs must be willing to change their practices regarding remuneration in selected areas and prospective data collected to determine cost effectiveness. Alternatively, programs that changed reimbursement can be studied to determine impact. It will be important to give such programs enough time to adjust to changes in compensation policies; failure to do so may result in terminating experiments or changes that have initially negative impacts. 


\section{V: CONCLUSIONS AND RECOMMENDATIONS FOR STRENGTHENING CBD PROGRAMS}

\section{V.1 Findings on Program Limitations}

\section{$\Rightarrow$ Recording and Reporting CBD Outputs}

- The existing systems of keeping records and reporting are inadequate.

- While more than 20 percent of CBD agents' time is spent providing information, counseling and referral services for Maternal-Child health $(\mathrm{MCH})$, Primary Health Care (PHC) and other reproductive and sexual health issues, not all programs keep records of these activities.

- Consequently, use of the number of family Planning (FP) acceptors, referrals, and CYP generated from FP services as the only indicators of CBD Program performance only provides a partial accounting of the total CBD program output.

- In both the Tanzania mainland and Zanzibar Ministry of Health programs, CBD output records are not available at all the supervision and management levels. This inhibits their use in continuous monitoring and evaluation of program performance at all levels.

\section{Recommendations}

- Each program should review its reporting format and procedures to ensure that all the reproductive and general health services provided by the CBD agents are recorded and records available and utilized in decision making in all the management and supervision levels.

- The programs require technical assistance in establishing computerized record keeping for ease in information storage, retrieval, and use.

- As the coordinator of FP activities in the country, FPU should formulate national guidelines on appropriate indicators to be used in evaluating and comparing performance of CBD programs.

- In addition, FPU needs to develop guidelines on a national reporting system and keep records of outputs of the CBD programs operating in the country. This will be valuable information to help in decision making about the expansion of the CBD Program in the country. 


\section{V.2 Factors Related to Program Output and Effectiveness}

\section{$\Rightarrow$ The expansion of the $C B D$ training curriculum to include reproductive}

and sexual health as well as $\mathrm{MCH}$ issues is a move towards the right direction.

- Agents are happy to provide a wide range of services

- Agents who have not been trained on all these aspects requested updates because the communities they serve request these services.

- Agents providing integrated FP and reproductive or Primary Health Care services have higher output than those providing only FP services.

\section{$\Rightarrow$ Remuneration is positively associated with the number of visits per agent}

- CBD agents provided with monetary remuneration see more clients and generate more Couple Years of Protection (CYP) than those provided with non-monetary incentives. In addition, agents provided with non-monetary incentives have better output than agents who are not provided with non-monetary incentives.

$\Rightarrow$ Program supervision and management characteristics have a higher impact on CBD output than factors such as agents' operation in urban or rural-based communities and high or low contraceptive prevalence rate (CPR) sites.

- In programs having both rural and urban sites, agents operating in urban sites did not necessarily perform better than their counterparts serving in rural districts.

- Within programs having high, medium, and low CPR sites, agents in high CPR districts did not necessarily have better performance than their counterparts operating in lower CPR areas. Only the Dodoma FPU sites that have a high level of unmet need (and medium CPR) performed better than their counterparts operating in areas having a medium level of unmet need.

- Agents identified monthly individual supervisory contacts, participation in program managed and sponsored income generating activities (IGAs), and strong community support as important motivating factors to their work.

- Programs having frequent individual supervisory contacts, IGAs, and strong community participation and support of CBD activities performed better than programs lucking or weak in these factors. For example, agents from the MOH Zanzibar program, who also had the 
lowest output per CBD, complained about their luck of individual supervisory contacts with their supervisors and a system to encourage community leaders' support of their activities.

\section{$\Rightarrow$ Monetary remuneration, while an important factor in motivating agents to produce higher outputs, does not necessarily guarantee job satisfaction.}

- Agents provided with monetary remuneration complained about inadequate remuneration more than the volunteer agents provided with non-monetary remuneration did.

- Agents having IGAs, which are sponsored and managed by their program, appear to have a higher level of job satisfaction and CBD retention rates than programs without IGAs.

- Community recognition is a significant factor in CBD motivation.

\section{$\Rightarrow$ There exist some similarities and variations in the nature of services provided by $C B D$ programs.}

- In general, agents have their greatest impact as a source of supply for non-clinical rather than referral methods. The SDA program is an exception in that its agents generate more CYP through referral for clinical methods than supply methods.

- SDA has a bias on pill supply while UMATI is more balanced in its provision of both pill and condom supplies.

- One of the reasons for SDA reliance on pill is the program's reliance on female CBD agents. In programs having both male and female agents, overall, the female agents' performance was better than that of their male counterparts. However, male agents distributed more condoms than their female counterparts.

\section{Recommendations}

- CBD agents trained before the implementation of the expanded CBD curriculum should have refresher courses covering elements they had not covered in their initial training and agents should be offered frequent refresher courses to be up-dated on developments in reproductive and sexual health field.

- Programs with weak or no community participation in the activities of the CBD programs should design strategies to involve community leaders in the management and running of CBD activities in their respective areas.

- To increase motivation of CBD agents (and enhance prospects for sustainability), programs relying on volunteer agents should consider introducing program sponsored and managed IGAs. 
- Programs having very few or no male CBD agents should review their recruitment policy and practices with a view to increasing male participation as service providers and users of community-based reproductive health services.

- Programs should implement the national CBD supervisory guidelines and reduce the ratio of number of CBD agents to one supervisor in areas where supervisors have a heavy workload.

\section{V.3 Program Costs and Cost Effectiveness}

$\Rightarrow$ UMATI, the program relying on volunteer agents provided with non-monetary incentives, is the most cost-effective program. However, the programs' variation in costeffectiveness ratios cannot be attributed solely to variations in remuneration strategies. A number of other factors that could not be fully controlled affect the programs' output.

$\Rightarrow$ There are significant variations in each program's cost structure, which affect costeffectiveness. SDA spends a large proportion of its budget on remuneration, FPU on supervision and training, and UMATI in training. FPU training costs are significantly higher than those of UMATI and SDA.

\section{Recommendations}

- Programs that pay little or no compensation, but have high training, supervision, and other costs to support their agents, may want to consider using more of their budget to compensate agents while reducing other costs.

- Improving factors such as supervision and community participation in and support of CBD activities will raise output and consequently improve cost-effectiveness.

- In preparing for declines in donor funding, programs need to take a broader focus than simply slashing salaries or payments to agents. The full budget should be examined so as to determine how the program could best survive with lower funding from donors.

- To learn how remuneration affects cost-effectiveness, operations research designs that control for program differences not associated with remuneration are required. 


\section{Appendix I. Evaluating the Impact of Annualizing Initial Training Costs Over Different Time Periods}

The table below shows the impact of changing the time period over which initial training costs are annualized. The greater the number of years over which training costs are annualized, the more favorable are the cost effectiveness ratios for FPU and UMATI. This is because these programs spend a high percentage of their costs on initial training. The cost-visit ratio for SDA remains largely unchanged because its initial training costs make up such a small proportion of its costs. The most important finding, however, is that the basic conclusion remains unchanged; that is, the cost effectiveness ratio is most favorable for UMATI no matter the time period over which costs are annualized.

Adjusted Average Annual Cost per Visit in which Training Costs are Annualized Over Different Time Periods by Program for 1995-96 (in US Dollars)

\begin{tabular}{|l|c|c|c|}
\hline Program & $\begin{array}{c}\text { Initial Training } \\
\text { Annualized } \\
\text { over Five Years }\end{array}$ & $\begin{array}{c}\text { Initial Training } \\
\text { Annualized } \\
\text { over Ten Years }\end{array}$ & $\begin{array}{c}\text { Initial Training } \\
\text { Annualized } \\
\text { over Twenty } \\
\text { Years }\end{array}$ \\
\hline FPU & 5.42 & 4.94 & 4.70 \\
\hline SDA & 1.71 & 1.65 & 1.62 \\
\hline UMATI & 1.34 & 1.09 & 0.97 \\
\hline
\end{tabular}

